\title{
Experimental Study on Shear Failure Characteristics of Jointed Rock Mass Based on Direct Shear Tests and Digital Image Correction Techniques
}

\author{
Fenhua Ren $\mathbb{D}^{1,2}$ Liwei Zhang, ${ }^{1,2}$ Xinghui $W u \mathbb{D}^{1,2}$ and Wensheng Liu ${ }^{1,2}$ \\ ${ }^{1}$ School of Civil and Resource Engineering, University of Science and Technology Beijing, Beijing 100083, China \\ ${ }^{2}$ Beijing Key Laboratory of Urban Underground Space Engineering, School of Civil and Resource Engineering, \\ University of Science and Technology Beijing, Beijing 100083, China
}

Correspondence should be addressed to Xinghui Wu; wuxinghui92@163.com

Received 30 October 2020; Revised 6 December 2020; Accepted 5 January 2021; Published 21 January 2021

Academic Editor: Sanjay Nimbalkar

Copyright (C) 2021 Fenhua Ren et al. This is an open access article distributed under the Creative Commons Attribution License, which permits unrestricted use, distribution, and reproduction in any medium, provided the original work is properly cited.

The instability of rock engineering is normally dominated by the shear failure of rock mass. The dip angle of discontinuous planes widely existing in rock mass is a key parameter affecting the shear strength and failure mode of jointed rock. This paper aims to investigate the influence of discontinuous joints on the shear failure of rock. Direct shear tests are carried out on rock-like specimens with discontinuous joints in different dip angles. During the shear tests, the strain field is monitored in real-time by digital image correction (DIC) technology. Experimental results show that the shear strength, shear strain evolution, and failure mode for the jointed specimens are affected by the dip angles of the discontinuous joints. The maximum shear strain of specimens with joint angles of $45^{\circ}$ and $75^{\circ}$ increases gradually with the increase of shear loading. The maximum shear strain for the specimens with joint angles of $0^{\circ}, 15^{\circ}, 30^{\circ}, 60^{\circ}$, and $90^{\circ}$ increases sharply after the shear load reaches $80 \%$ of the peak load. When the joint inclination angle is less than $45^{\circ}$, the crack begins to expand from the joint tip and is interconnected to form a penetrating fracture. When the joint dip angle is greater than $45^{\circ}$, the cracks initiate at the joint tip and then propagate at different paths resulting in multistage shearing and crushing failure.

\section{Introduction}

The instability and failure of rock engineering, e.g., slopes, tunnels, and mining stopes, are mainly caused by the shear failure of rock mass [1-3]. As discontinuous joints are widely existing in rock mass, the shear failure of jointed rock is significantly affected by the joints distributions. Moreover, the stress field concentration and distribution for the rock with discontinuous joints are determined by the joint angle during the shear loading. For understanding the shear failure mechanisms of jointed rock and improving the stability of rock engineering, it is of great significance to investigate the shear strength and failure characteristics of discontinuous jointed rock mass.

Over the past few decades, considerable researches have been carried out on the mechanical properties of the rock mass structural plane under the shear loading. Lajtai $[4,5]$ studied the failure mode of jointed plaster by direct shear tests. He divided the failure modes of jointed plaster into three types: tensile failure, shear failure, and crushing failure. Direct shear test is an effective method to study the effect of shear stress on jointed rock mass, which can simulate the shear stress state of jointed rock mass. Gehle [6] improved the ordinary direct shear test by using a servo control system to control the shear loading rate. Li et al. [7] made rock-like samples by concrete and carried out rock joint strength characteristic tests under different shear rates, fluctuation angles of rock structural planes, and normal stress. Xi et al. [8] used the artificial intelligence neural network to predict the meso fracture characteristics of the concrete interface transition zone. They obtained the relationships between strength characteristics of rock structural plane and shear 
rate, fluctuation angle, and normal stress. Yang et al. [9] carried out the uniaxial compression test on fissured fine sandstone with different shapes and analyzed the influence of fissure on the rock mass failure mode. They found that the failure mode mainly included tensile failure, shear failure, and combined tensile shear failure for different widths of the rock bridge. Yang et al. [10] carried out shock compression test on red sandstone and grey sandstone and limestone body specimens by using the split Hopkinson compression bar (SHPB) test system. The testing results show that the failure of red sandstone was mainly shear failure, and that of limestone was mainly tensile failure, accompanied by local shear failure. Although the shear failure mechanism of the structural plane is complex, numerical simulation can effectively reflect the micro and macromechanical properties of rock [11-13]. Selvadurai and $\mathrm{Yu}$ [14] carried out numerical simulation of the joint direct shear test by using the continuum finite element method, and the numerical calculation results were coincided with the joint shear test results. Wang et al. [15] used PFC2D to explore the shear strength law of anchored joint surfaces with different roughness. The shear test and numerical model were used to study the mechanical properties of intact rock samples, but fewer researches were about discontinuous jointed rock mass.

As a kind of complex engineering-geological body, there are a large number of discontinuous joints such as joints, fissures, and faults with different scales in natural rock mass $[16,17]$. Prudencio and Van Sint Jan [18] carried out compression tests on discontinuous joint specimens and found three basic failure modes: plane failure, step failure, and overturning failure of newly generated blocks. Bahaaddini et al. [19] used PFC, a particle flow simulation software, to study the influence of geometric parameters of discontinuous joints on mechanical properties of rock mass under uniaxial compression. There should be five failure modes according to his study, including intact fracture mode and block fracture mode. Zhu et al. [20] carried out direct shear tests on intermittent jointed rock mass, and it was found that the main failure mode was composite interface failure. Liu and Xia [21] analyzed the mechanical characteristics and theory of direct shear test of discontinuous jointed rock mass and proposed the transfixion failure mode of discontinuous jointed rock mass. Chen and Li [22] used CT scanning technology to conduct real-time scanning on the nontransfixion fracture specimen during the loading process and carried out an experimental study on the fracture propagation law of the nontransfixion fracture medium during uniaxial compression. Yang et al. [23] carried out the uniaxial compression test on brittle marble with discontinuous prefabricated fractures by using the MTS815 rock servo testing machine. The experimental results show that the uniaxial compressive strength, peak axial strain, and elastic modulus of rock mass gradually decreased with the increasing of crack number, length, and dip angle, while the fracture spacing and angle of the rock bridge had little effect on the mechanical parameters above. Chen [24] prepared the sample model with discontinuous joint group by rock-like materials and obtained five failure modes of discontinuous joint group samples under the influence of joint group dip angle. With the advancement of experimental monitoring technology, it is possible to track the entire process of rock failure continuously by using digital image correlation (DIC) technology [25]. The DIC method is a noncontact, high-precision full-field observation technology based on digital image technology. At present, this technique provides a useful tool for rock failure analysis. Many studies have applied DIC technology to explore the evolution of the deformation field of rock surface [26], expansion of preexisting cracks [27-29], and fracture process of rocks during compression [30-32].

In this paper, a series of rock-like specimens are made with different dip angles $\left(0^{\circ}, 15^{\circ}, 30^{\circ}, 45^{\circ}, 60^{\circ}, 75^{\circ}\right.$, and $\left.90^{\circ}\right)$. Direct shear tests are carried out on the jointed specimens. DIC system is employed to monitor the surface strain field of the specimens constantly during the shear process. The shear strength and shear strain evolution for the specimens are obtained. The effects of the joint dip angle on the peak strength, shear strain evolution, and failure mode are analyzed and discussed.

\section{Experimental Method or Procedures}

2.1. Specimens Preparation. Figure 1 shows the specimen design with dimensions of $100 \mathrm{~mm} \times 100 \mathrm{~mm} \times 30 \mathrm{~mm}$. The cement mortar with a specification of M7.5 is used to make rock samples with a water-cement ratio of 0.45 . Steel slices are inserted into the mold to form the discontinuous planes. Figure 2 shows the specimen preparation processes and the finally jointed specimens. The specimens with the joint dip angle $0^{\circ}, 15^{\circ}, 30^{\circ}, 45^{\circ}, 60^{\circ}, 75^{\circ}$, and $90^{\circ}$ are named as A- 0 , A-15, A-30, A-45, A-60, A-75, and A-90, respectively.

2.2. Testing Methods and DIC Brief Principles. The rock shear test machine (TFD-20H/50J) of Changchun Keyi Testing Instrument Co., LTD is used in direct shear tests. The normal maximum load is $20 \mathrm{kN}$, and the tangential maximum load is $50 \mathrm{kN}$. Horizontal and axial loading is controlled by displacement, and the loading rate is $0.5 \mathrm{~mm} / \mathrm{min}$. In order to record the deformation characteristics of the specimens during the shearing process, DIC equipment is used to monitor the surface deformation of the specimens. Digital image correlation (DIC) is a method to spray a random pattern called speckles pattern on the surface to be measured and to analyze the deformation degree of samples by comparing and analyzing the images before and after deformation. It can detect not only the amount of deformation but also the direction of deformation. The bending and deformation of objects can be quantified in a noncontact and nondestructive way. The layout of the test equipment is shown in Figure 3(a). The digital cameras are used to collect speckle images on the surface of the specimens during the test process at a high frequency. The data acquisition system runs synchronously with the mechanical test machine. The displacement and deformation data of the specimens in the full-field and fulltime domain are collected. The quality of speckle fabrication determines the accuracy of strain field data during the compression test. After the specimen is made and formed, a thin layer of white paint is sprayed on the surface of the 


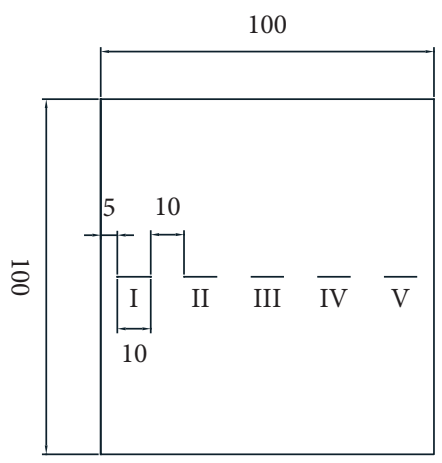

(a)

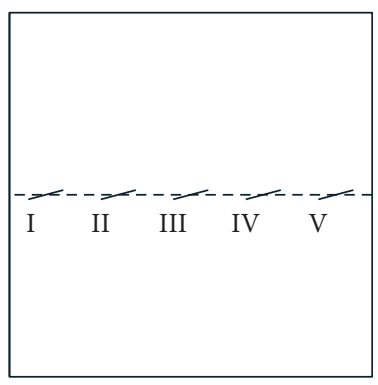

(b)

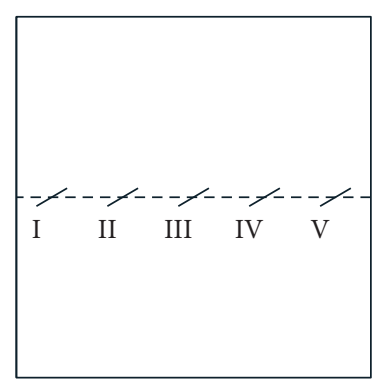

(c)

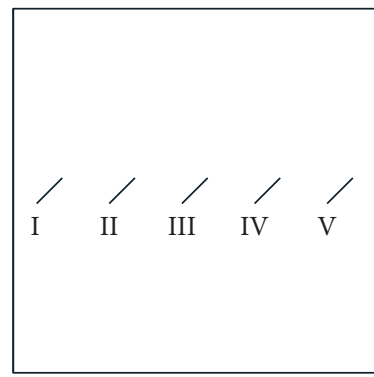

(d)

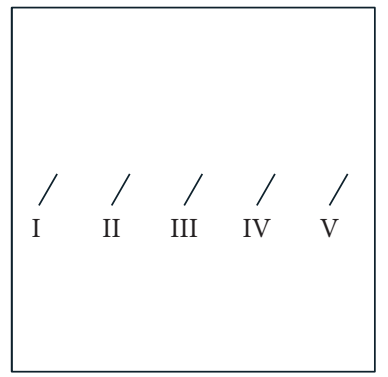

(e)

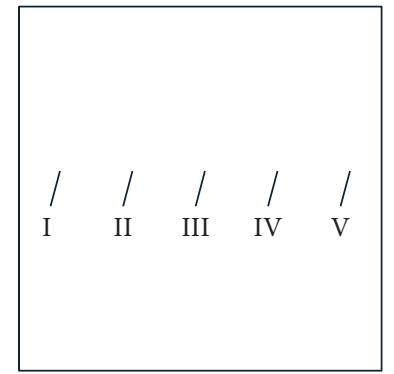

(f)

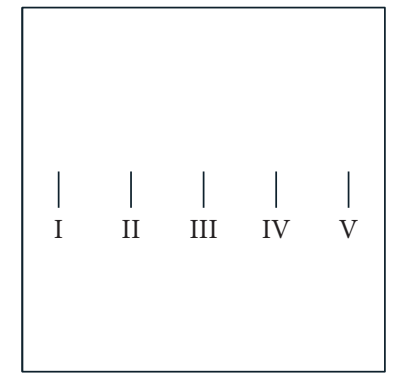

(g)

Figure 1: Schematic diagram of rock samples with different joint dip angles: (a) $0^{\circ}$, (b) $15^{\circ}$, (c) $30^{\circ}$, (d) $45^{\circ}$, (e) $60^{\circ}$, (f) $75^{\circ}$, and (g) $90^{\circ}$.

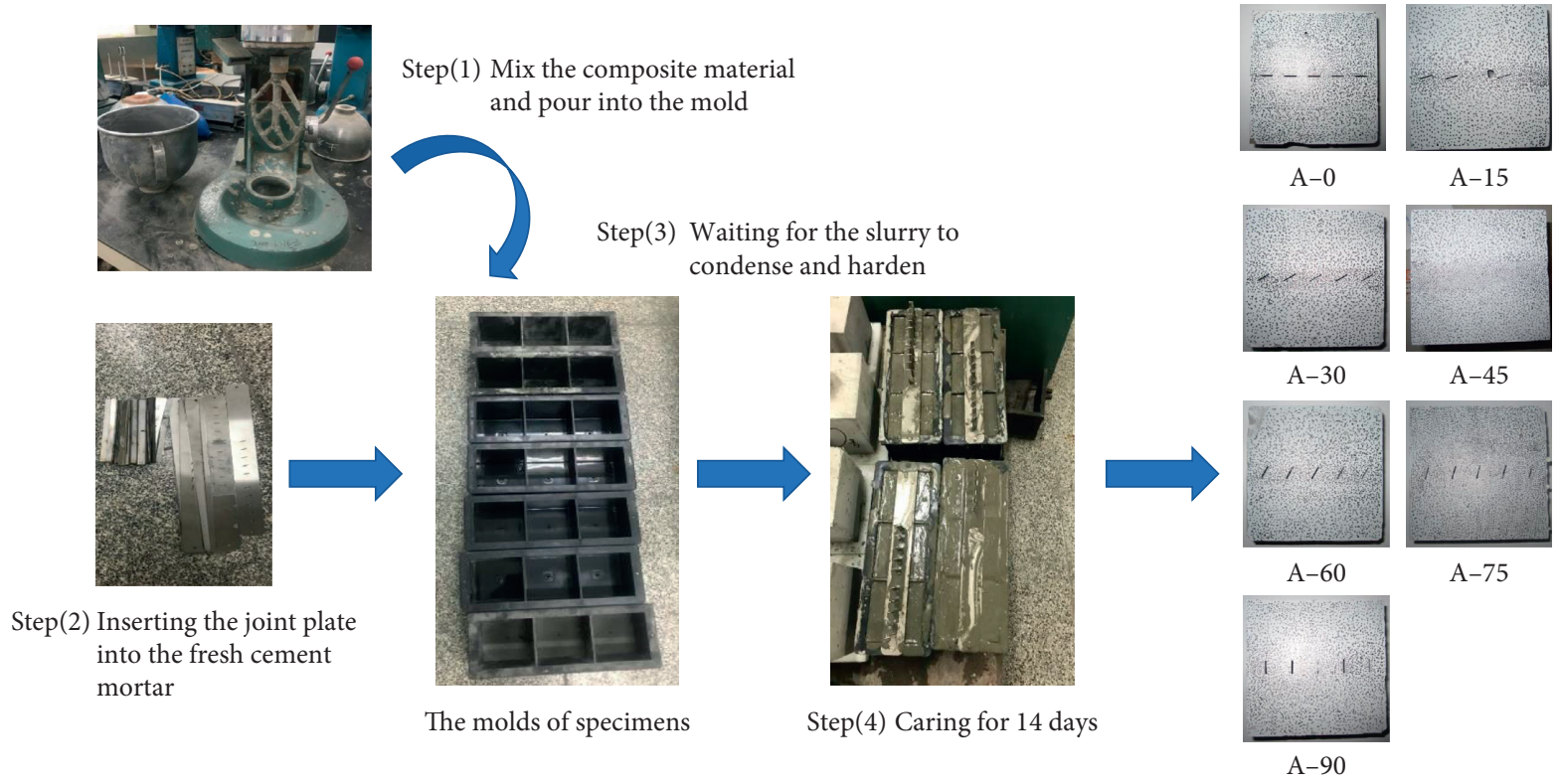

FIGURE 2: Preparation process of specimens with different joint dip angles.

specimen. After the white paint dries, nonuniform speckle black spots are manually produced on the surface. The variation characteristics of the strain field near the fracture are traced by making more scattered spots with different sizes and uneven distribution.

\section{Experimental Results}

3.1. Stress-Displacement Curve and Strength. Figure 4 shows the shear stress-strain relation curves of specimens with different joint dip angles. It can be seen that the shear load increased continuously with the increase of shear displacement until suddenly decreasing, and then, the shear load remained stable due to friction. With the increasing of dip angle, the peak shear load presented a significant fluctuation. In general, it presents a gradual increase with the increasing of dip angle. The results show that the peak shear load of the specimens with a dip of $90^{\circ}$ is significantly lower than that of the $75^{\circ}$ specimens. The main reason was that the transfixion cracks parallel to the preset cracks appear in the 


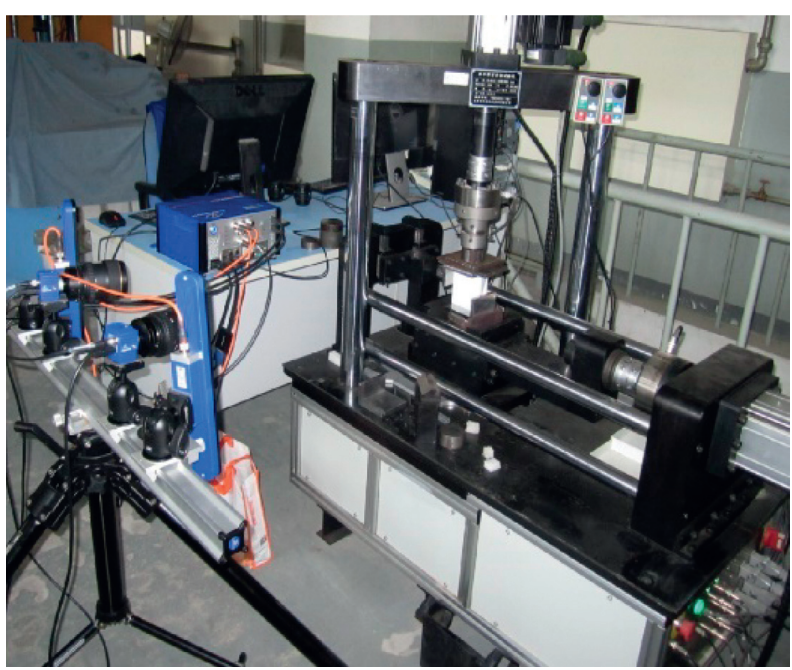

(a)

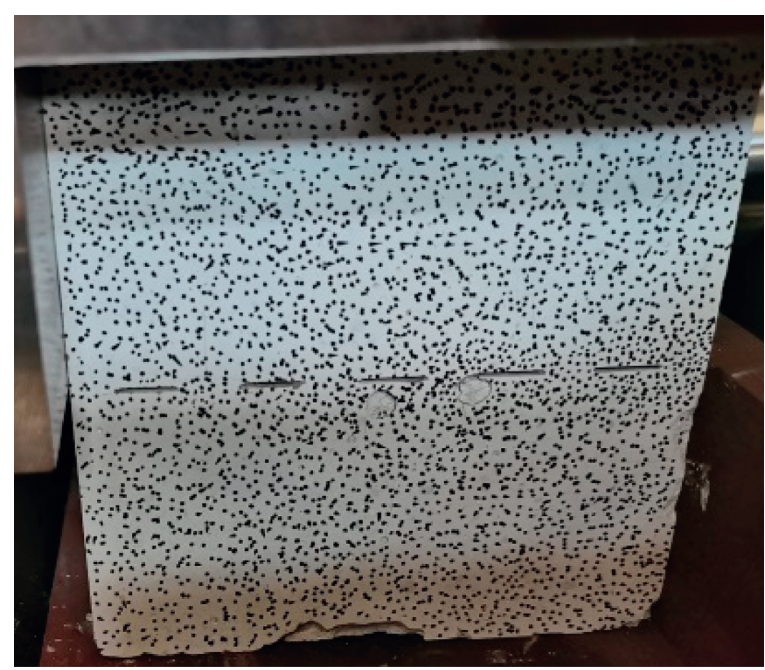

(b)

FIGURE 3: Direct shear equipment and specimen layout: (a) direct shear and DIC equipment and (b) specimen installation.

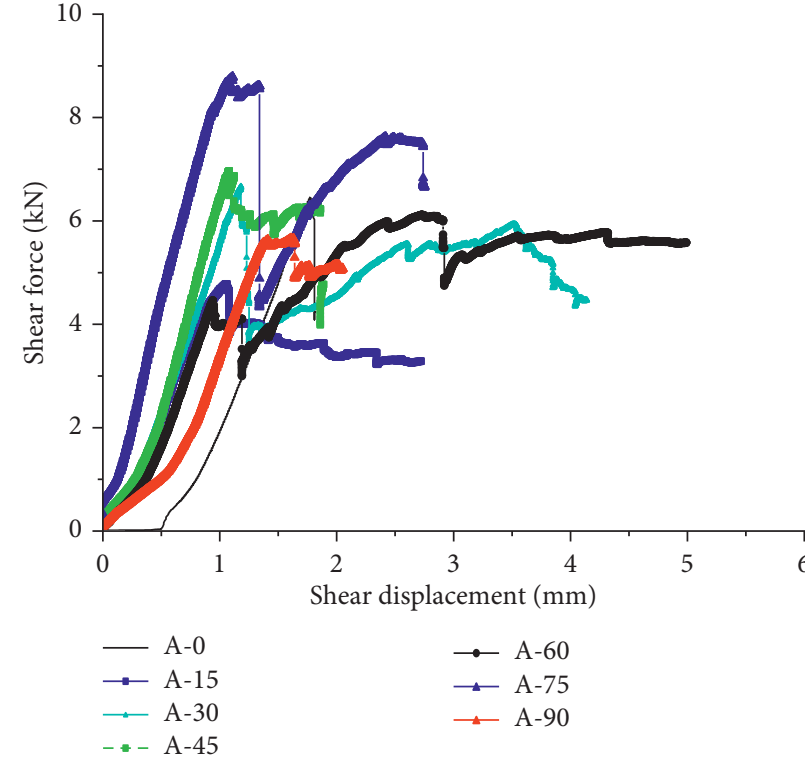

(a)

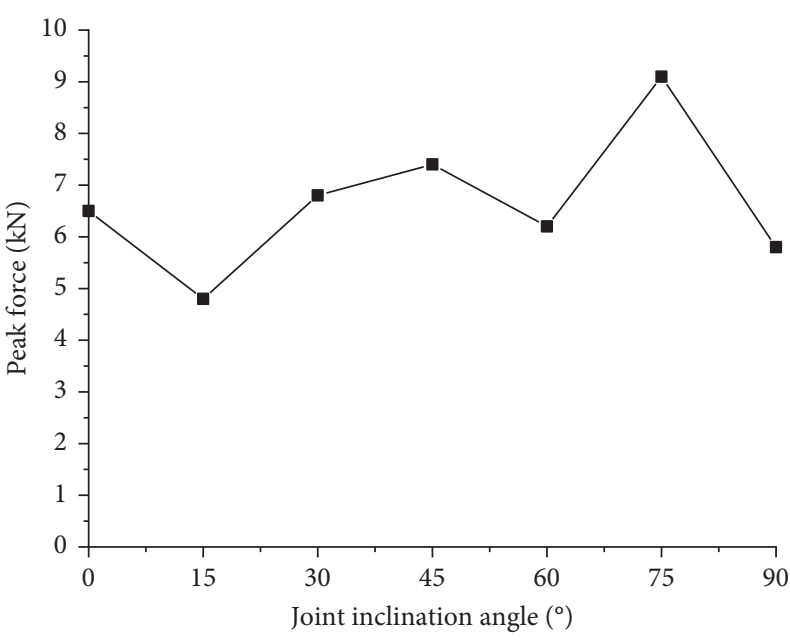

(b)

FIGURE 4: Shear mechanical properties of different fracture dip models: (a) the stress-strain curves of joint dip angles and (b) peak stressjoint dip angle curve.

initial stage of the direct shear process of the model. After that, although the transfixion cracks gradually appeared in the shear direction, the overall shear strength was greatly reduced.

3.2. DIC Strain Evolution Processes. Figure 5(a) shows the failure modes of specimens with different preset fracture dip angles. It was found that, for the $0^{\circ}$ to $30^{\circ}$ dip angle specimens, the cracks initiate at the tip of the joint. The cracks generated by the adjacent fractures are directly connected to each other, eventually forming a transfixion fracture. When the dip angle of the fracture is higher than $45^{\circ}$, the crack is also initiated at the joint tip, and a secondary crack approximately extends along the loading direction. The secondary crack may stagger along different paths. Finally, the rock bridges between the joints were crushed. The number of cracks between fractures increased gradually and the multistage failure phenomenon appears, which leads to the fluctuation of shear stress after the peak shear load (Figure 4). Figure 5(b) shows the distribution of shear strain of the specimens after shear failure obtained by the DIC system. It can be found that the peak shear strain mainly concentrates near the pre-existing joint tip. Therefore, 

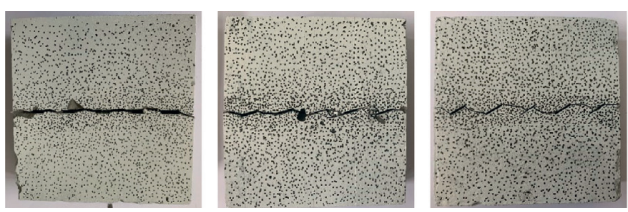

A-15
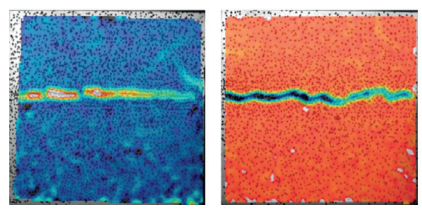

A-30

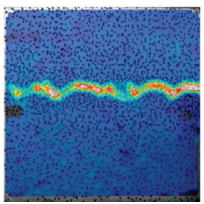

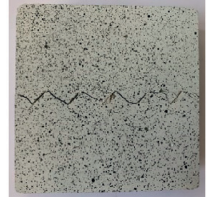

(a)

A-45

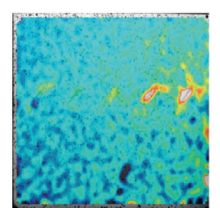

(b)
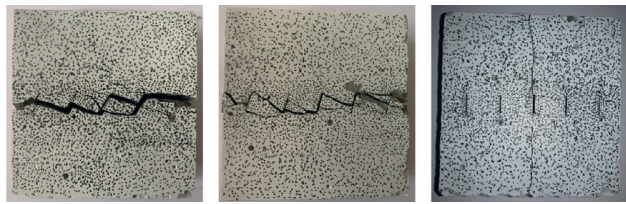

A-60

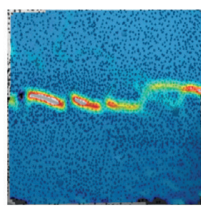

A-75

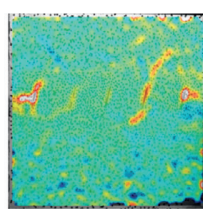

A-90

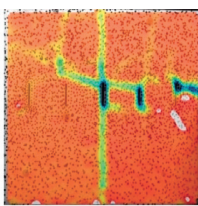

FIGURE 5: Effect of the joint dip angle on the shear failure: (a) the results of the specimen failure and (b) contour map of the principal strain field on the surface of the specimens.

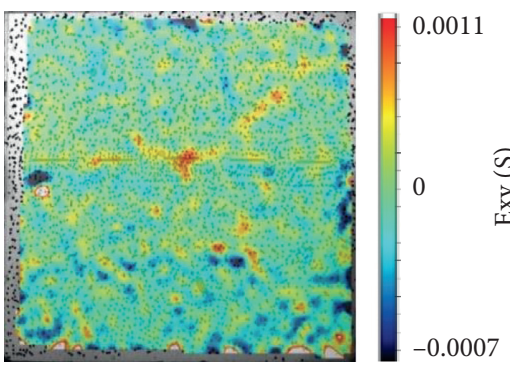

(a)

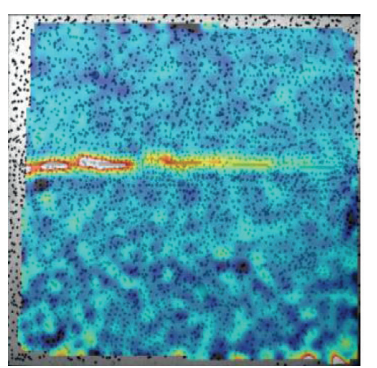

(d)
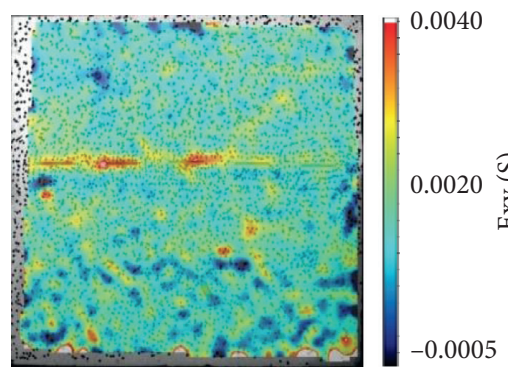

(b)

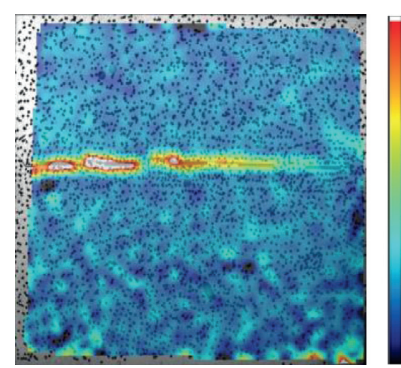

(e)

0.022

$-0.003$

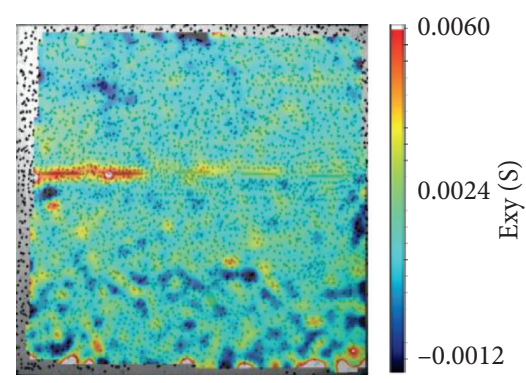

(c)

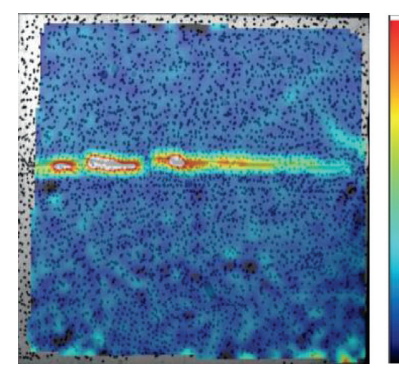

0.0400

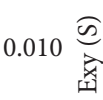

(f)

Figure 6: Shear strain evolution of joint specimens $\left(0^{\circ}\right)$ : (a) $10 \%$ peak stress, (b) $30 \%$ peak stress, (c) $50 \%$ peak stress, (d) $70 \%$ peak stress, (e) $90 \%$ peak stress, and (f) $100 \%$ peak stress.

the shear stress concentration is mainly distributed at the fracture tip. The failure modes from DIC monitoring have a good agreement with real failure modes.

\section{Shear Deformation Evolution and Failure Process of Rocks with Different Joint Dip Angles}

The evolution process of the shear strain of joint specimens with a dip angle of $0^{\circ}$ is shown in Figure 6 . It can be seen that when $10 \%$ of the peak load is applied, a small deformation occurs in the joint area in the middle of the specimen. When
$30 \%$ of the peak load is applied, the strain in the middle region increases and the deformation and failure develop along the direction of joint load. Then, with the increase of load, the left joint is connected when the applied load reaches $70 \%$ of the peak load. With the applied load increases to $100 \%$ of the peak load, the deformation, and failure develop from the middle to the right side of the joint until the joint is completely transfixion failure. Generally, the deformation on the left side of the joint specimen is more obvious, and the degree of failure decreases successively from left to right.

Figure 7 shows the evolution process of the maximum shear strain of the dip angle $0^{\circ}$ joint specimen. When $10 \%$ 


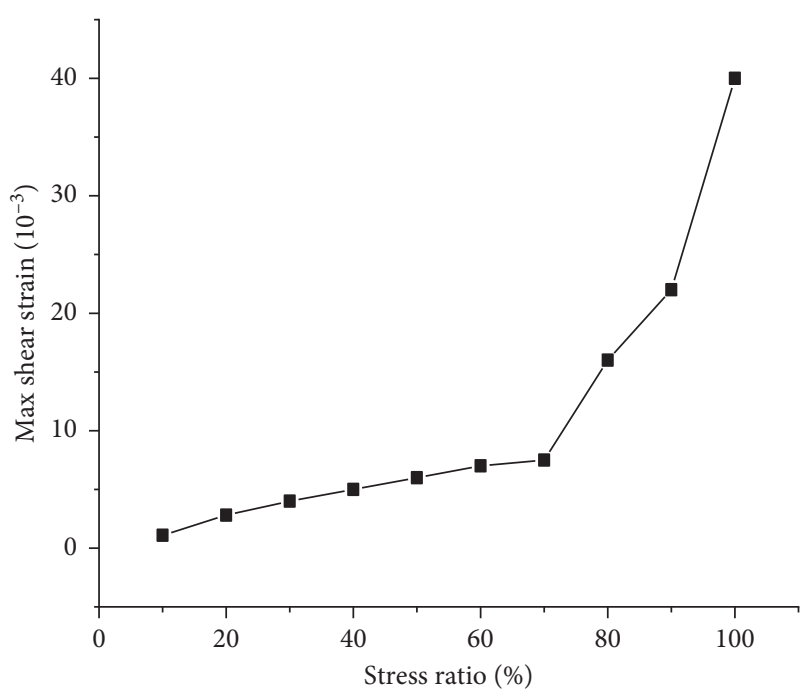

Figure 7: Maximum shear strain evolution $\left(0^{\circ}\right)$.
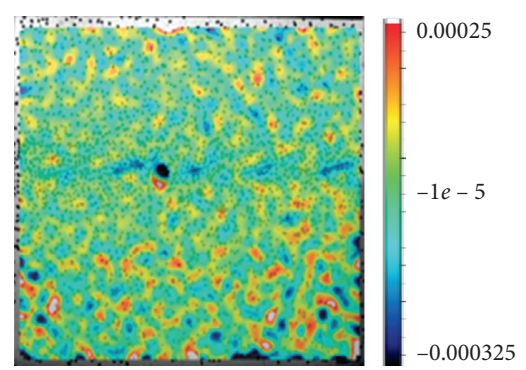

(a)

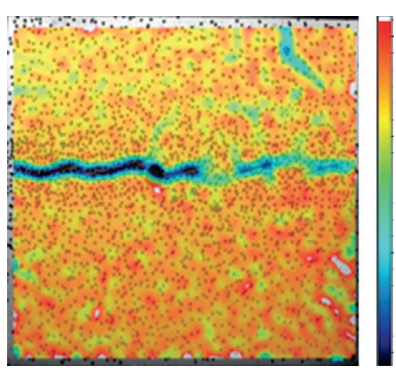

(d)

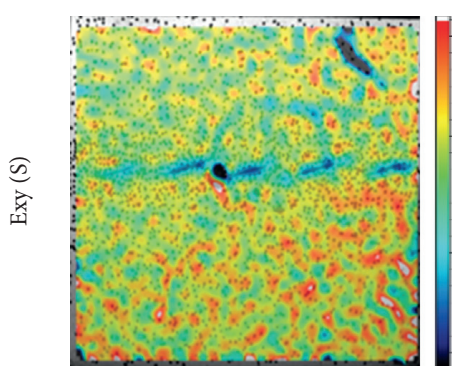

(b)

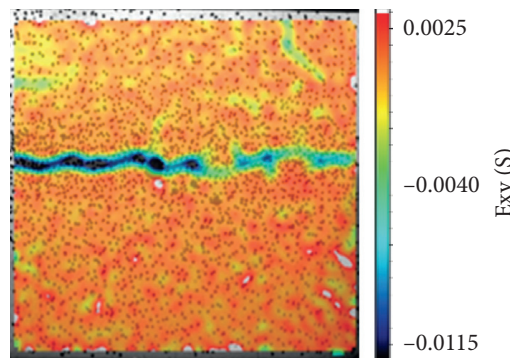

(e)

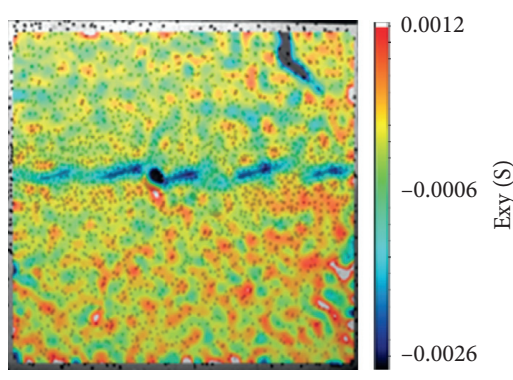

(c)

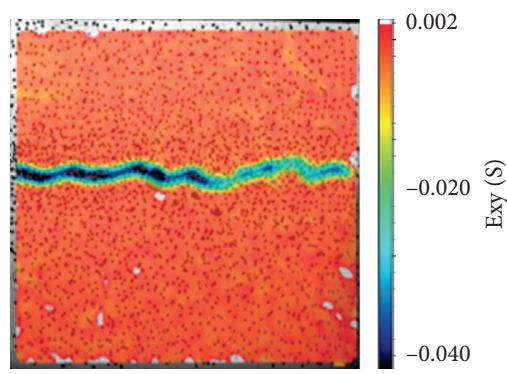

(f)

Figure 8: Shear strain evolution of joint specimens (15 ): (a) $10 \%$ peak stress, (b) $30 \%$ peak stress, (c) $50 \%$ peak stress, (d) $70 \%$ peak stress, (e) $90 \%$ peak stress, and (f) $100 \%$ peak stress.

$70 \%$ of the peak load is applied, the maximum shear strain of the joint specimen is less affected. With the increase of load level, the maximum shear strain of the joint specimen increases significantly with the increase of the load after reaching $80 \%$ of the peak load. The shear deformation becomes more obvious, and the jointed specimen is obviously fractured until reaching the peak load. In Figure 7, the $X$-axis represents the ratio of the current stress to the peak stress, and the $Y$-axis represents the maximum shear strain.

Figure 8 shows the evolution process of shear strain of the dipping $15^{\circ}$ joint specimen. As shown in the figure, when
$10 \%$ of the peak load is applied, some joint positions of the specimen are deformed. When $30 \% \sim 50 \%$ of the peak load is applied, the deformation mainly concentrates on the joints in the middle of the specimen. When the applied load reaches $70 \%$ of the peak load, the deformation failure expands from the middle to the left and right sides of the specimen.

When the load increases to $100 \%$ of the peak load, the deformation and failure are mainly concentrated in the left joint and the joints are connected.

Figure 9 shows the evolution process of the maximum shear strain of the dipping $15^{\circ}$ joint specimen. It can be 


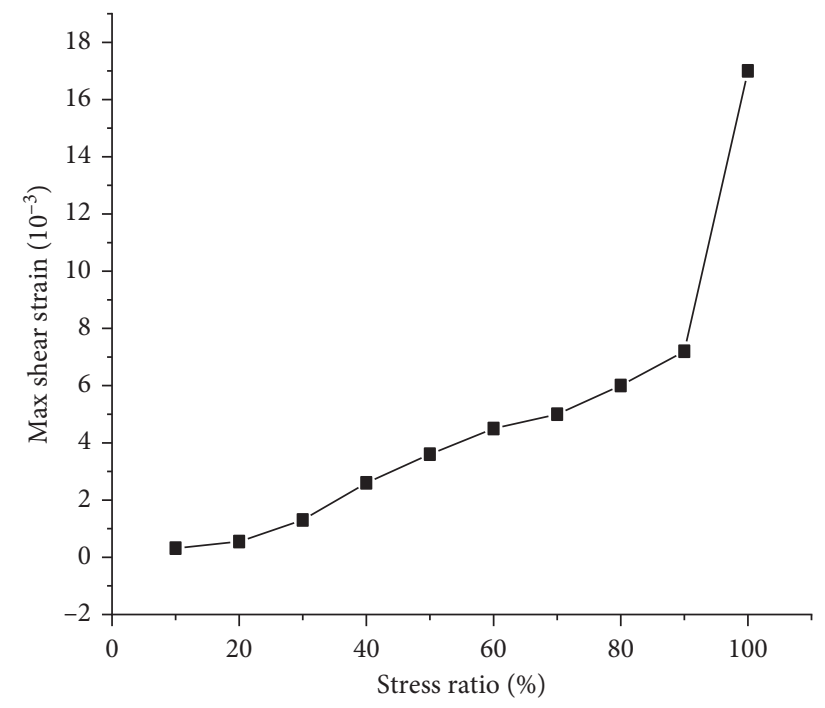

FIgURE 9: Maximum shear strain evolution $\left(15^{\circ}\right)$.

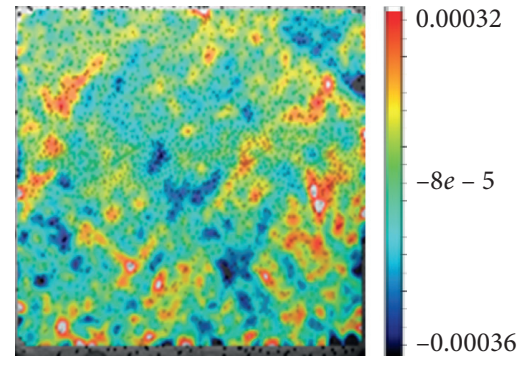

(a)

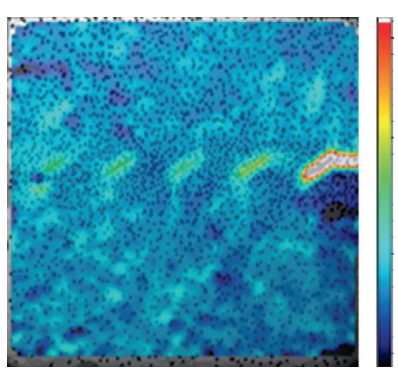

(d)

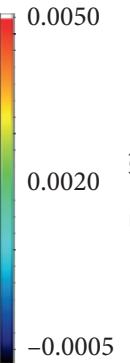

$-0.0005$

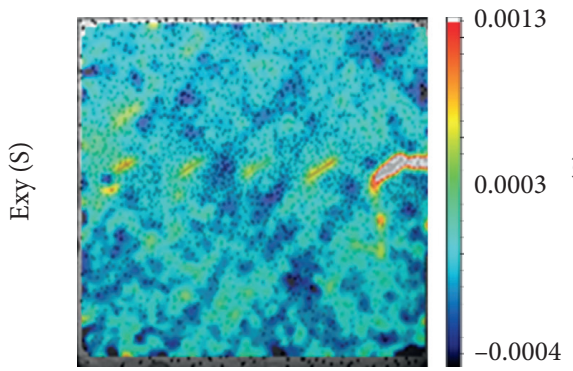

(b)
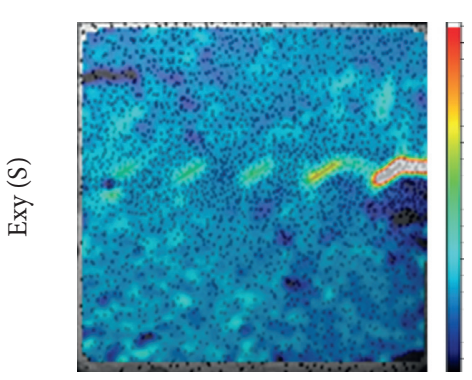

(e)

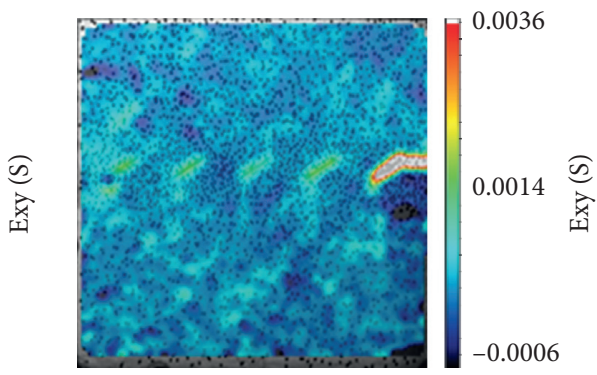

(c)

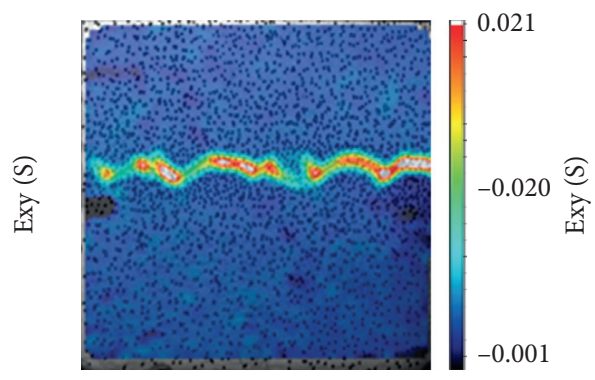

(f)

Figure 10: Shear strain evolution of joint specimens (30 ): (a) $10 \%$ peak stress, (b) $30 \%$ peak stress, (c) $50 \%$ peak stress, (d) $70 \%$ peak stress, (e) $90 \%$ peak stress, and (f) $100 \%$ peak stress.

found that the maximum shear strain of joint specimens is less affected when $10 \% \sim 50 \%$ of the peak load is applied. In the peak load range of $60 \% \sim 90 \%$, the maximum shear strain increases obviously with the increase of load, and the specimen has obvious shear deformation. When $90 \%$ of the peak load level is applied, the maximum shear load increases rapidly, and the failure of joint specimens occurs.

Figure 10 shows the evolution process of shear strain of the dipping $30^{\circ}$ joint specimen. When $10 \%$ of the peak load is applied, the strain field distribution of the specimen is relatively dispersed, and there is no significant strain concentration area. When $20 \% \sim 90 \%$ of the peak load is applied, the deformation concentrates around the joints and increases with the increase of the load. When the load increased to $100 \%$ of the peak load, the joint deformation increases sharply, and all joints of the specimen are connected by fractures.

Figure 11 shows the evolution process of the maximum shear strain of the joint specimen with the dip angle $30^{\circ}$. Although the variation trend of the maximum shear strain is basically the same as that of the joint dip angle of $15^{\circ}$, the maximum shear strain under the peak load at the joint dip angle of $30^{\circ}$ is $42.5 \%$ of the maximum shear strain under the peak load at the joint dip angle of $15^{\circ}$. 


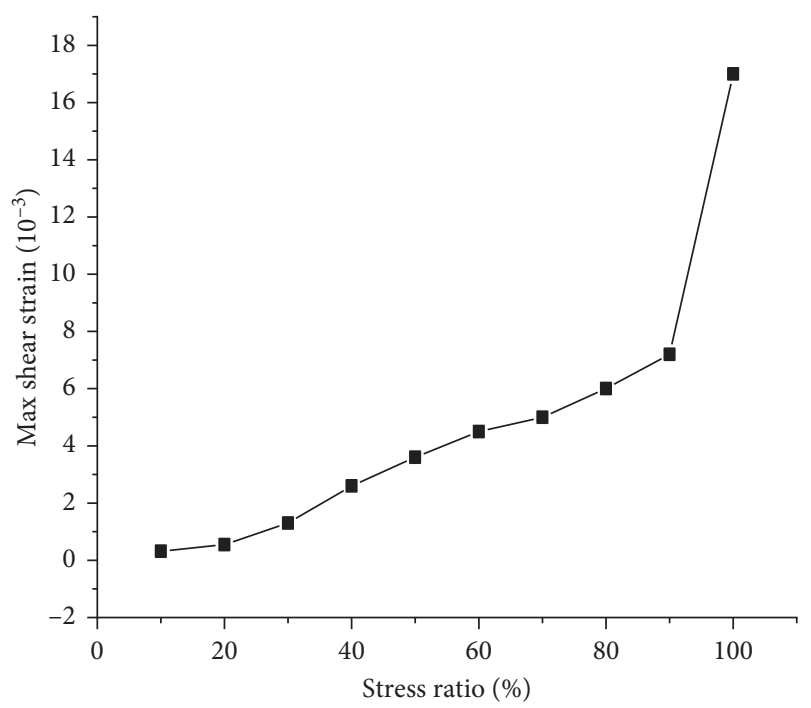

FIGURE 11: Maximum shear strain evolution $\left(30^{\circ}\right)$.
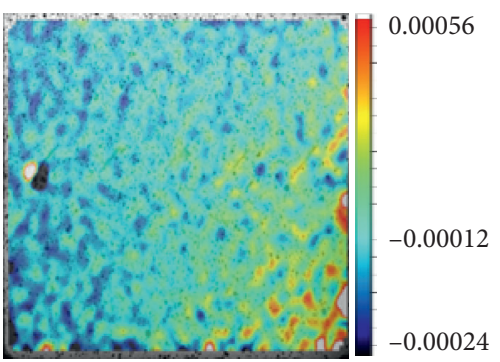

(a)

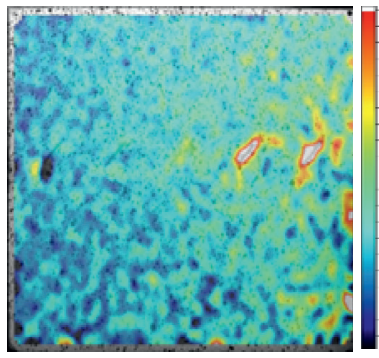

(d)

0.00095

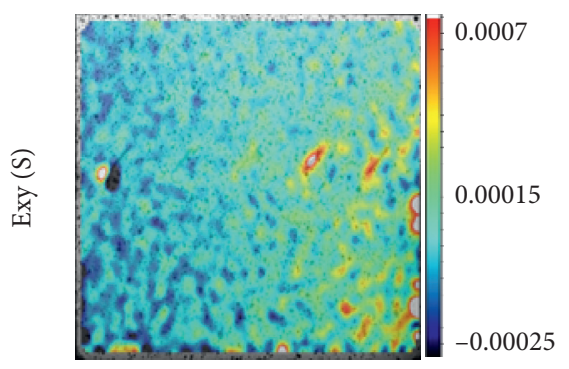

(b)

(3)

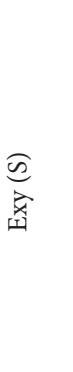

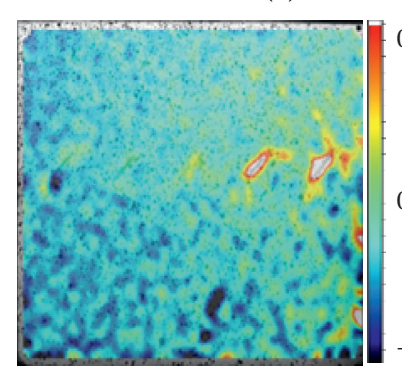

(e)

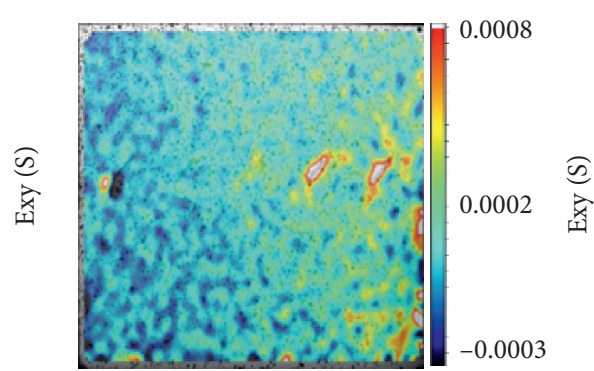

(c)

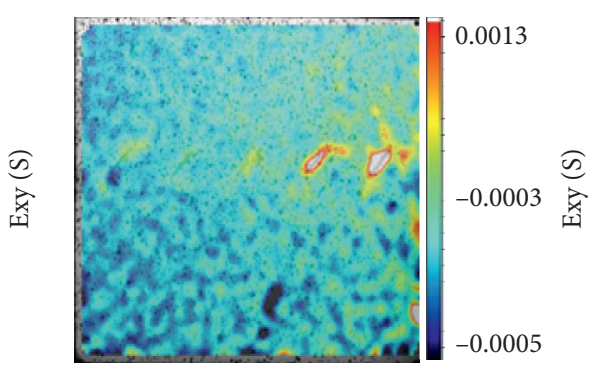

(f)

FIGURE 12: Shear strain evolution process of joint specimen $\left(45^{\circ}\right)$ : (a) $10 \%$ peak stress, (b) $30 \%$ peak stress, (c) $50 \%$ peak stress, (d) $70 \%$ peak stress, (e) $90 \%$ peak stress, and (f) $100 \%$ peak stress.

Figure 12 shows the evolution process of the maximum shear strain of the joint specimen with the dip angle of $45^{\circ}$. When $10 \%$ of the peak load is applied, the surrounding strain of the right joint is relatively concentrated. With the increase of the load level, the deformation of the two joints on the right side increases continuously. However, until the load reaches $100 \%$ of the peak load, no overall penetration deformation occurs in the joint specimen. Figure 13 shows the evolution process of the maximum shear strain of the dipping $45^{\circ}$ joint specimen. It can be seen that the maximum shear strain of the joint specimen increases gradually with the increase of load. However, the maximum strain value at
$100 \%$ of the peak load is small, and there is no sudden increase similar to the maximum shear strain of $0^{\circ}, 15^{\circ}$, and $30^{\circ}$ joint specimens near $100 \%$ of the peak load.

Figure 14 shows the evolution process of shear strain of joint specimen with a dip angle of $60^{\circ}$. As shown in the figure, when $10 \% \sim 30 \%$ of the peak load is applied, the strain around the joint increases with the increase of the load. When $10 \% \sim 30 \%$ of the peak load is applied, a strain concentration area perpendicular to the joint appears between the joints, and the deformation gradually increases with the increase of the load. When $70 \% \sim 100 \%$ of the peak load is applied, it can be seen that the strain around the joint 


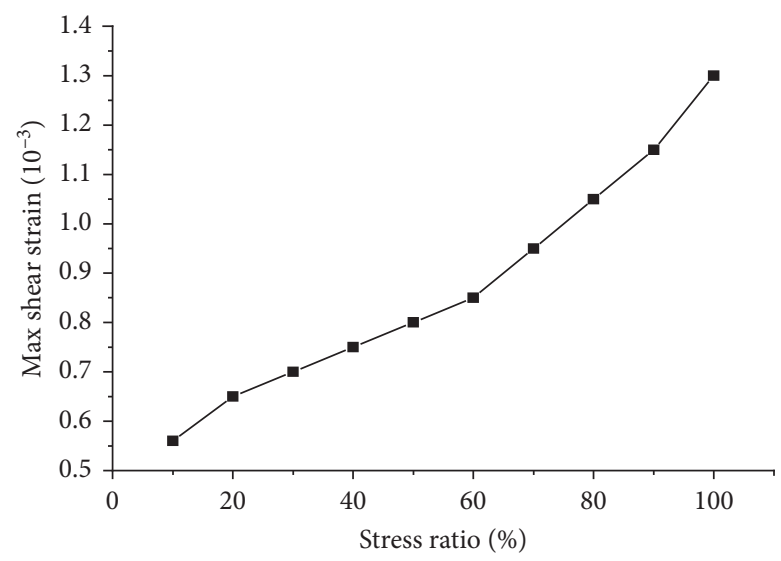

Figure 13: Maximum shear strain evolution $\left(45^{\circ}\right)$.

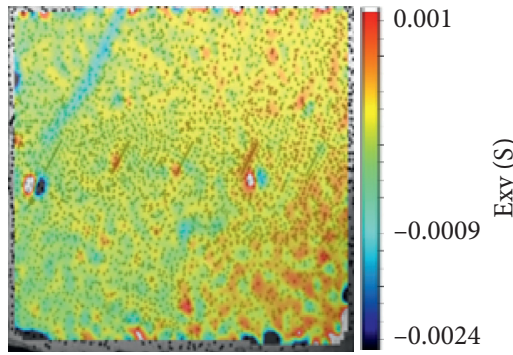

(a)

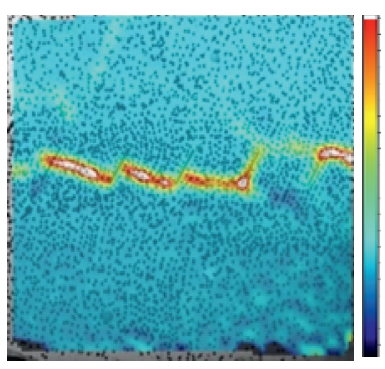

(d)

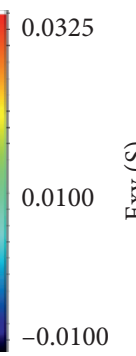

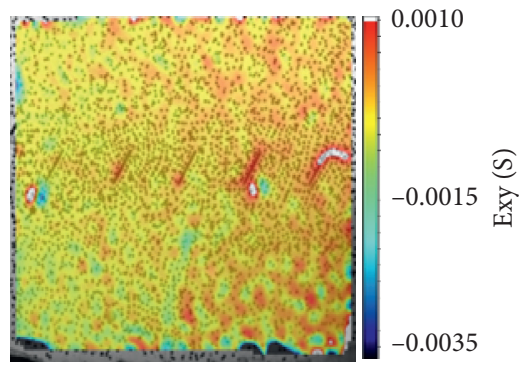

(b)

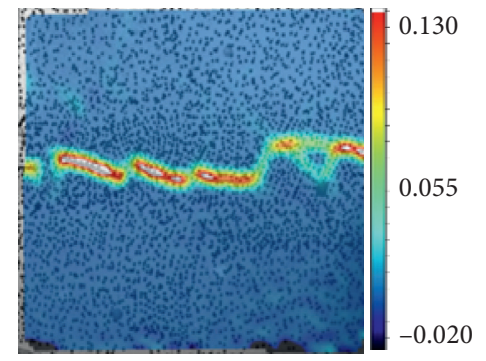

(e)

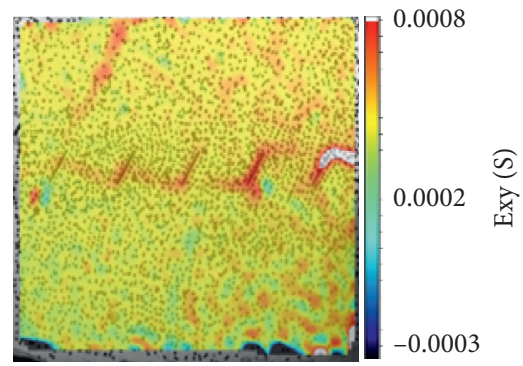

(c)

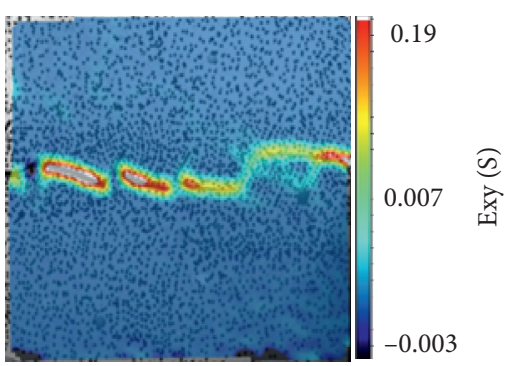

(f)

Figure 14: Shear strain evolution process of joint specimen $\left(60^{\circ}\right)$ : (a) $10 \%$ peak stress, (b) $30 \%$ peak stress, (c) $50 \%$ peak stress, (d) $70 \%$ peak stress, (e) $90 \%$ peak stress, and (f) $100 \%$ peak stress.

weakens, the deformation and failure between the two vertical joints gradually increases, and finally penetrates the joint specimen, which leads to a significant deformation and failure. Figure 15 shows the evolution process of shear strain of the joint specimen with a dip angle of $60^{\circ}$. It can be seen that the maximum shear strain decreases when $10 \%$ 20\% of the peak load is applied. When $20 \% \sim 60 \%$ of the peak load is applied, the maximum shear strain increases with the increase of the load. When $60 \% \sim 80 \%$ of the peak load is applied, the shear strain increases significantly. When $80 \%$ $100 \%$ of the peak load is applied, the shear strain increases rapidly and the joint specimen is significantly fractured.

Figure 16 shows the evolution process of shear strain of the joint specimen with a dip angle of $75^{\circ}$. It can be seen that the strain around the joint increases with the increase of load, especially for the joint I, IV, and V. However, when the peak load reached $100 \%$, the joint specimen does not penetrate transversely. Figure 17 shows the evolution process of shear strain of joint specimens with a dip angle of $75^{\circ}$, which is similar to that of joint specimens with a dip angle of $45^{\circ}$. With the increase of load, the maximum shear strain of joint specimens gradually increases. The maximum strain value at $100 \%$ of the peak load is small, and there is no sudden increase in maximum shear strain, showing a progressive failure characteristic.

Figure 18 shows the evolution process of shear strain of joint specimens with a dip angle of $90^{\circ}$. It can be seen from Figure 18 that when $10 \%$ of the peak load is applied, the central joint of the specimen produces deformation and failure perpendicular to the direction of the shear load, and 


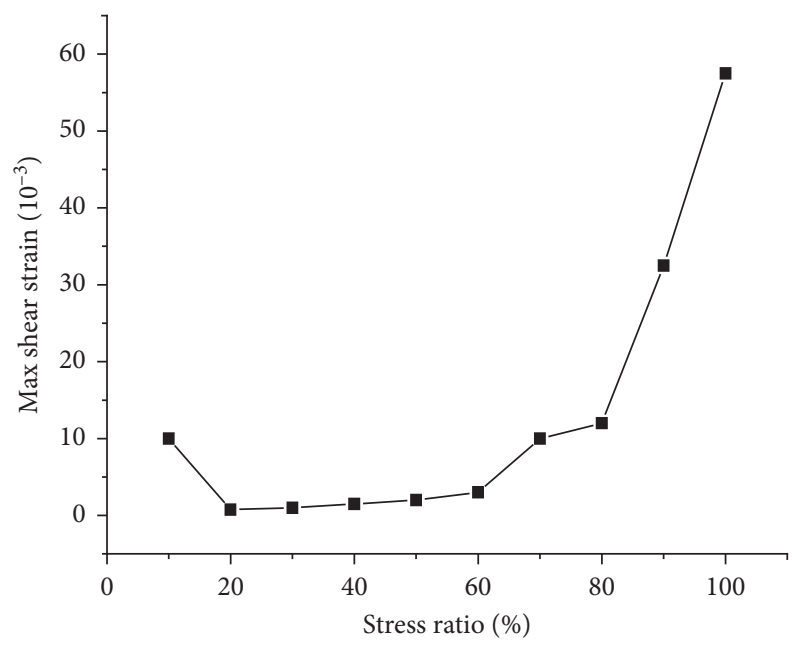

Figure 15: Maximum shear strain evolution $\left(60^{\circ}\right)$.
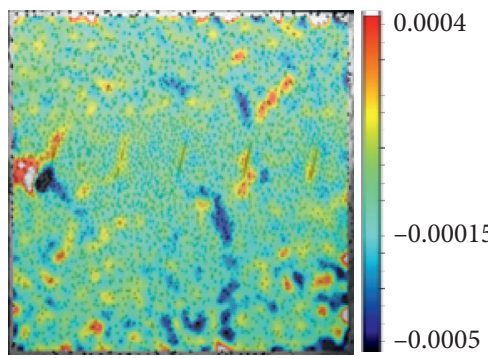

(a)

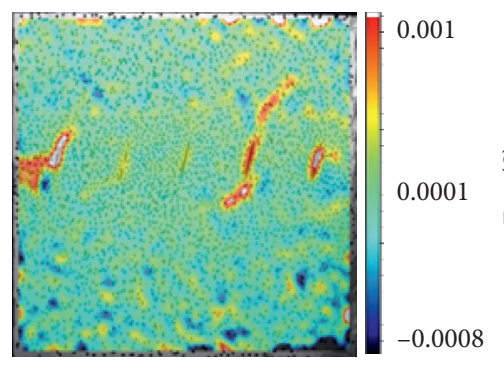

(d)

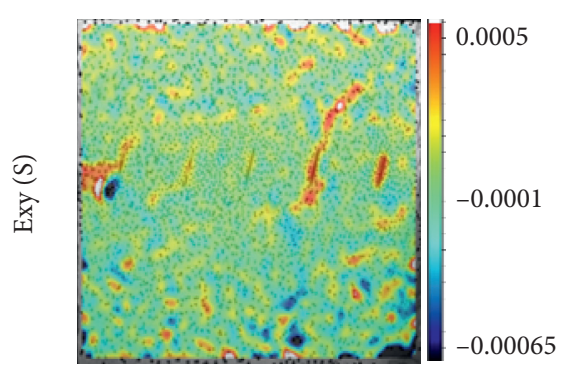

(b)

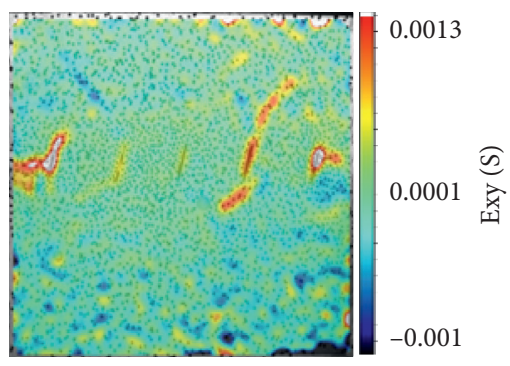

(e)

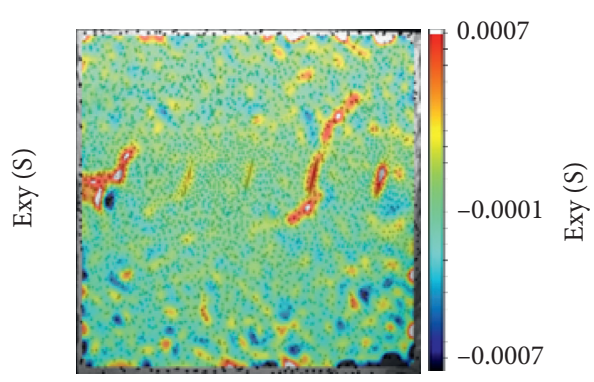

(c)

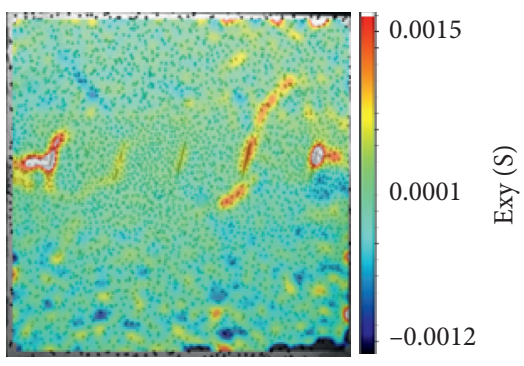

(f)

Figure 16: Shear strain evolution process of the joint specimen $\left(75^{\circ}\right):$ (a) $10 \%$ peak stress, (b) $30 \%$ peak stress, (c) $50 \%$ peak stress, (d) $70 \%$ peak stress, (e) $90 \%$ peak stress, and (f) $100 \%$ peak stress.

the deformation and failure continue to intensify as the load increases. When $70 \% \sim 80 \%$ of the peak load is applied, the strain around joints III and IV increases in the vertical and loading directions. Finally, when $100 \%$ of the peak load is applied, the transverse penetration failure occurs among the joints. Figure 19 shows the evolution process of the maximum shear strain of the joint specimen with a dip angle of $90^{\circ}$. When $10 \% \sim 40 \%$ of the peak load is applied, the maximum shear strain of the joint specimen increases rapidly. When $40 \% \sim 90 \%$ of the peak load is applied, the maximum growth rate of the shear strain slows down. When $90 \% \sim 100 \%$ of the peak load is applied, the maximum shear strain increases rapidly, and the failure of joint specimens intensifies.

Figure 20 compares the evolution process of the maximum shear strain for the specimens with different joint dip angles. It can be found that the maximum shear strain increases slowly at the initial stage with the increase of load level. For the specimens with joint dip angles $0^{\circ}, 15^{\circ}, 30^{\circ}, 60^{\circ}$, and $90^{\circ}$, when the load level increases from $80 \% \sim 90 \%$ of the peak strength to $100 \%$ of the peak strength, the maximum shear strain suddenly increases, which means a significant deformation and failure appears in the specimen. When the joint dip angle is $45^{\circ}$ and $75^{\circ}$, the maximum shear strain of 


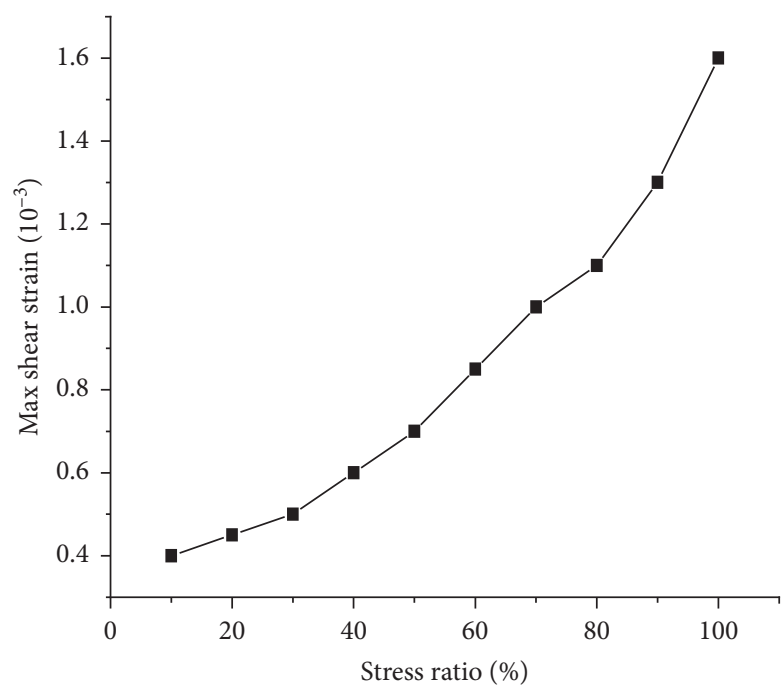

Figure 17: Maximum shear strain evolution $\left(75^{\circ}\right)$.

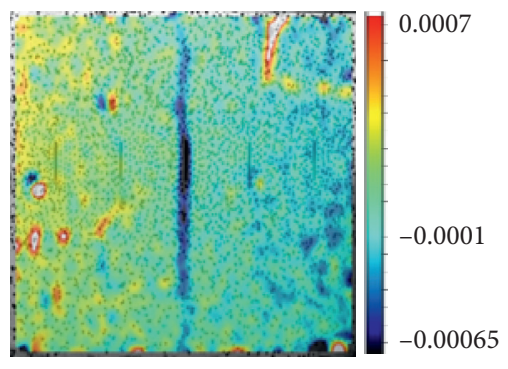

(a)

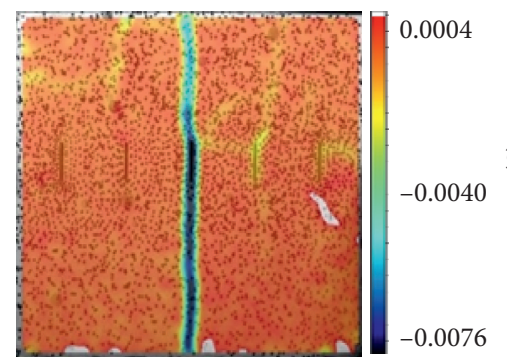

(d)

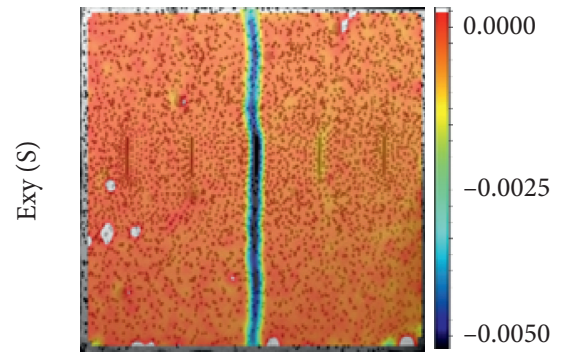

(b)

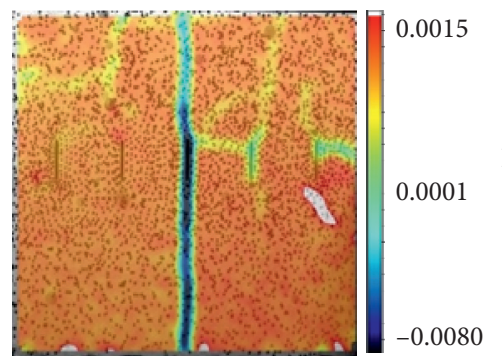

(e)

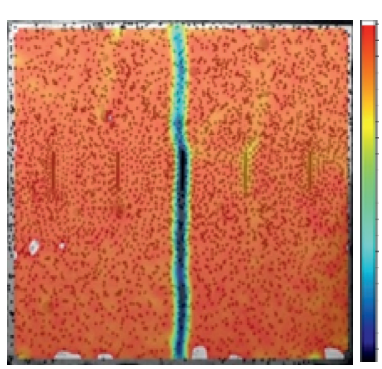

0.0000

(c)

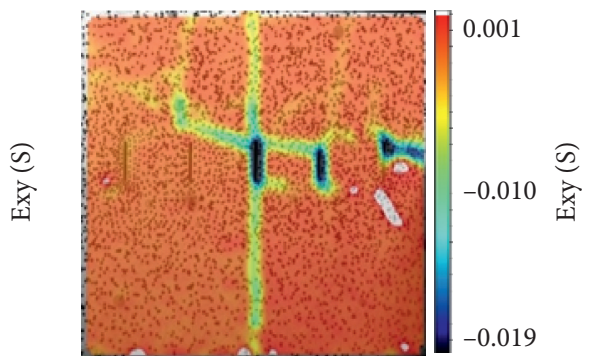

(f)

Figure 18: Shear strain evolution process of joint specimens $\left(90^{\circ}\right)$ : (a) $10 \%$ peak stress, (b) $30 \%$ peak stress, (c) $50 \%$ peak stress, (d) $70 \%$ peak stress, (e) $90 \%$ peak stress, and (f) $100 \%$ peak stress.

the specimens gradually increases with the increase of the load level. There is no sudden increase of strain at a high level, and the specimen does not appear overall transverse penetration failure.

Figure 21 shows the typical development process of shear failure of joint specimens with a dip angle of $0^{\circ}$. It can be seen that joint I cracks from the left edge and develops to joint II along the right side of the joint. Joint $\mathrm{V}$ cracks from the right edge to form a wing crack, and the cracks on both sides continue to expand into the specimen along the joint. Joint II stretches and opens to form a macro crack and develops along the right side of joint. Joint IV opens to form a wing crack, while shear crack of joint $\mathrm{V}$ opens to form right upper crack. Finally, the specimen is completely fractured along the joint direction.

Figure 22 shows the typical development process of shear failure of joint specimens with a dip angle of $15^{\circ}$. It is found that joint I cracks and opens from the left edge and then develops along the right side of the joint to the end. The joint II cracks and opens from the left end to the right end and then develops to joint $\mathrm{V}$, and finally, all joints are connected. Among them, joint IV cracks along the middle of the left side of the initial fracture to the right underlying end, showing a concave arc shape. Joint V cracks and opens from the left 


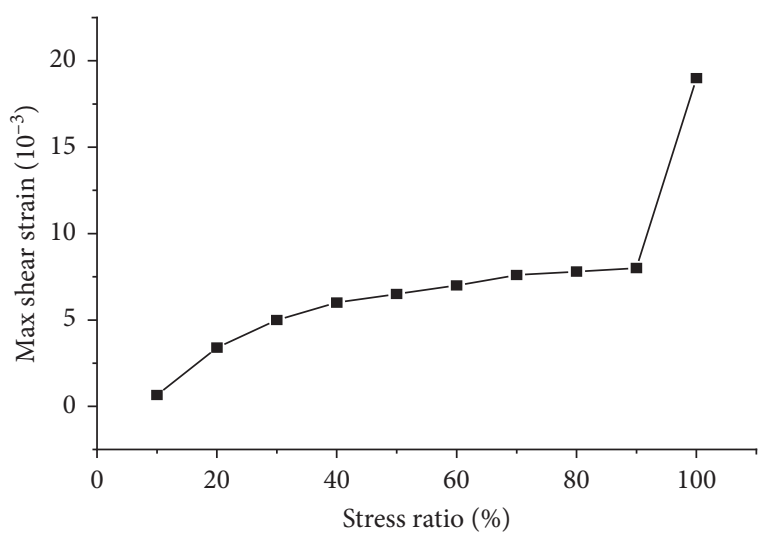

Figure 19: Maximum shear strain evolution $\left(90^{\circ}\right)$.

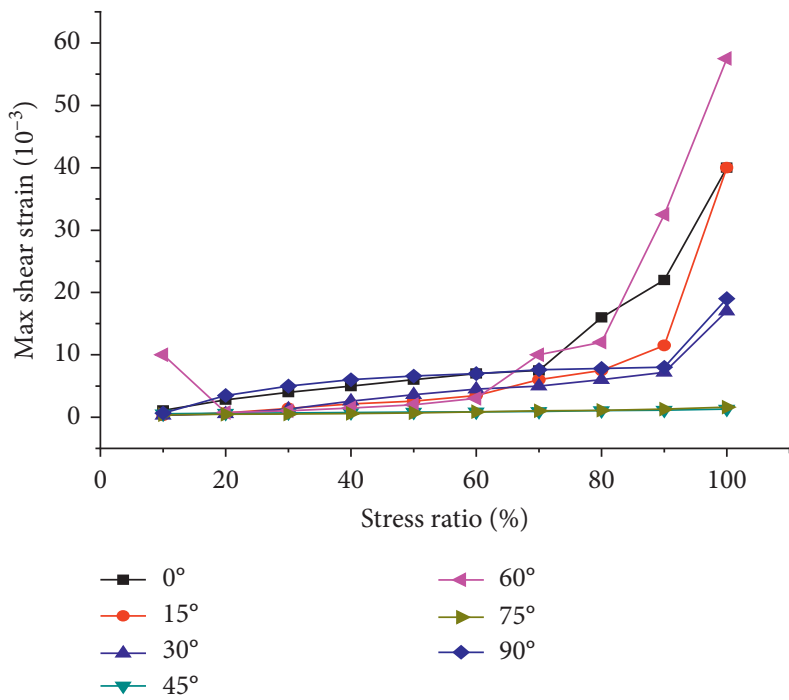

Figure 20: The effect of joint dip angle on the evolution of maximum shear strain.

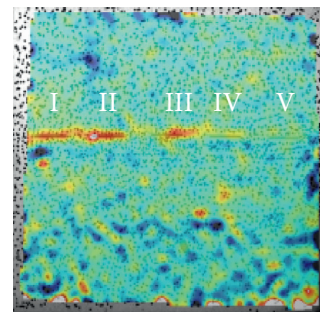

(a)

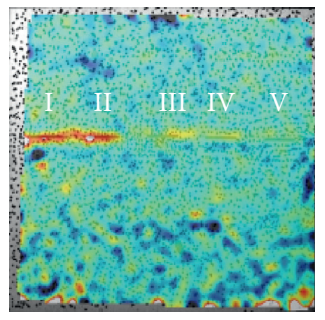

(b)

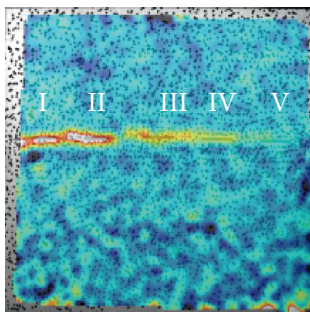

(c)

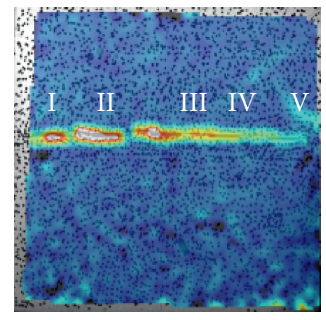

(d)

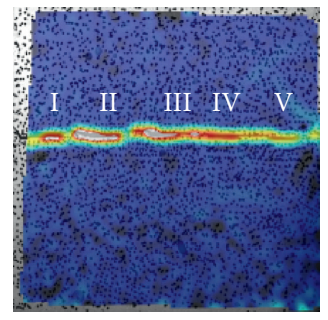

(e)

Figure 21: Failure process of joint specimens $\left(0^{\circ}\right)$.

warped end to the middle of the left side, showing a convex arc shape.

Figure 23 shows the typical development process of shear failure of joint specimens with a dip angle of $30^{\circ}$. It can be seen that the joint I started to crack from the right underlying end and extends to the left. The joint II starts to crack from the left joint to the underlying end of the right joint and extends from the right joint to the upper left. The joint III has an open crack from the left warped end to the middle of the joint on the right. The joint IV starts to crack from the left joint warping end and extends to the right and down without penetrating. Then, the joint IV cracks from the upper part of the underlying end of the right joint and expands to the upper left without penetrating. The joint $\mathrm{V}$ produces an upward convex fracture from the left warped end to the upper part of the underlying end of the right joint 


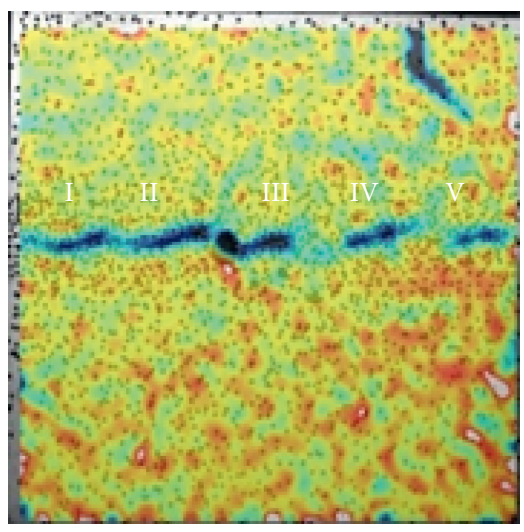

(a)

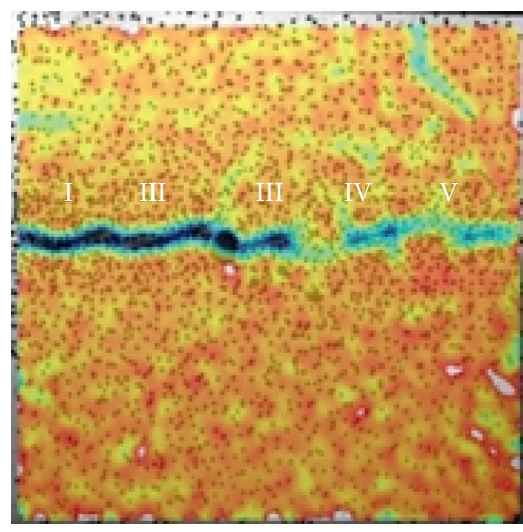

(b)

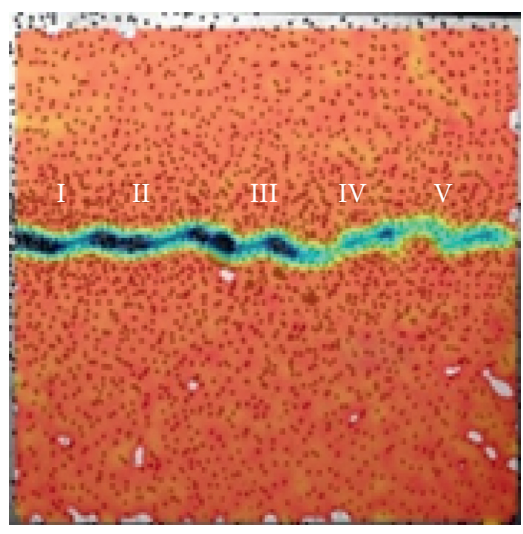

(c)

Figure 22: Failure process of joint specimens $\left(15^{\circ}\right)$.

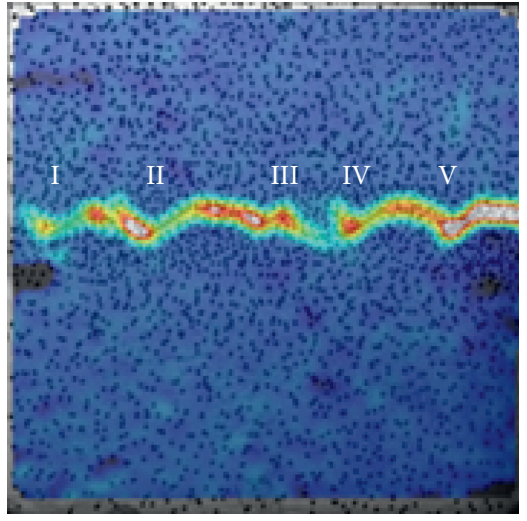

(a)

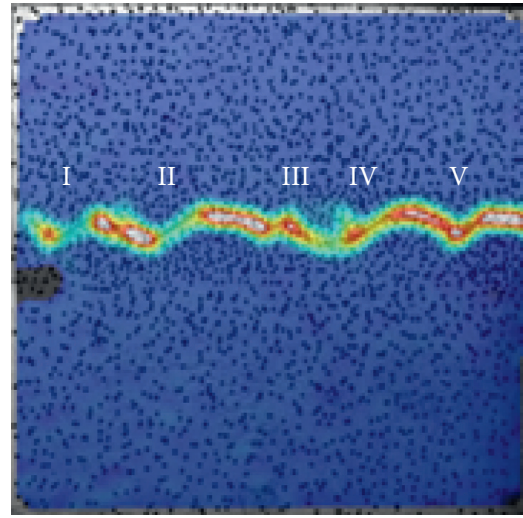

(b)

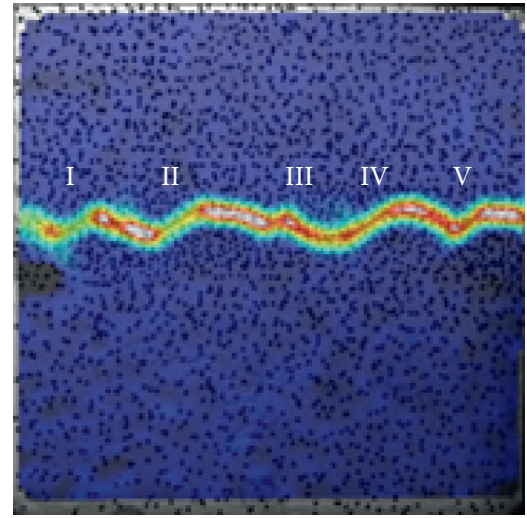

(c)

Figure 23: Failure process of joint specimen $\left(30^{\circ}\right)$.

and horizontally expands from the left warped end along with the initial defect by crossing the fracture. It can be seen from Figure 23(b) that the cracks of joints I and II are connected. The crack on the left side of joint II penetrates, and the right crack is slightly closed. It can be seen from Figure 23(c) that the crack on the right side of joint I expanded to the upper left side after approaching the joint and merges with the left crack at the edge of the specimen. Up to this point, all joints are connected, and the specimen is significantly fractured.

Figure 24 shows the typical development process of shear failure of joint specimens with a dip angle of $45^{\circ}$. It can be seen from Figures 24(a) and 24(c) that joint IV cracks from the up-warped end of the left joint to the underlying end of the right joint. It can be seen from Figure 24(b) that joint III cracks from $1 / 4$ of the up-warped end of the right joint, extends $15^{\circ}$ to the upper left, and exceeds joint II. It can be seen from Figure 24(c) that joint IV cracks from the upwarped end of the left joint to the underlying end of the right joint. The joint III cracks from the up-warped end of the left joint to the middle part of the right joint, and the middle part of the fracture points to the underlying end of the right joint.
The middle of the underlying edge of the specimen cracks vertically upwards. It can be seen from Figures 24(c) and 24(d) that joint $\mathrm{V}$ is inclined downward from the up-warped end of the left joint to the right edge, and the right edge of joint II is inclined upward to the left and finally the fracture penetrates.

Figure 25 shows the typical development process of shear failure of the joint specimen with a dip angle of $60^{\circ}$. It can be seen from Figure 25(a) that joint I forms a $T$-shaped cracking in the middle of the right joint, the underlying left branch extended to the underlying left by $30^{\circ}$ first and then turns to horizontal. The joint II and joint III both penetrate and crack from the middle of the left joint to the underlying end of the right joint. The joint IV penetrates and cracks from $1 / 4$ of the underlying end of the left joint to the lower end of the right joint. It can be seen from Figures 25(b) and 25(c) that the joint $\mathrm{V}$ cracks from the up-warped end of the left joint, expands horizontally to the left, and then expands horizontally to the right from the up-warped end of the right joint and connect with the right edge.

Figure 26 shows the typical development process of shear failure of the joint specimen with a dip angle of $75^{\circ}$. It can be 


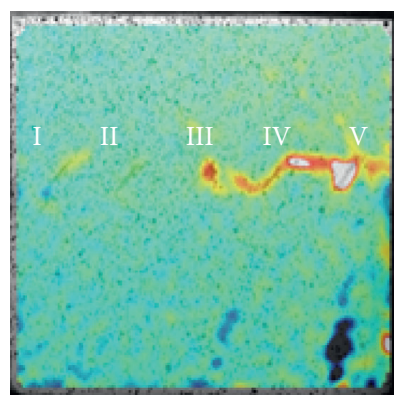

(a)

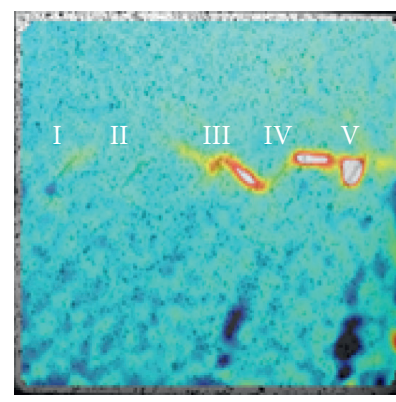

(b)

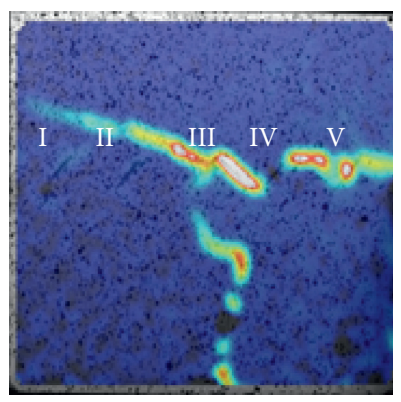

(c)

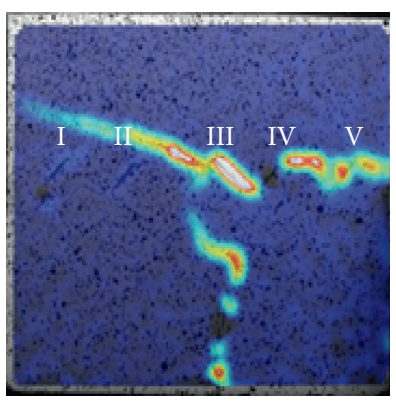

(d)

FIGURE 24: Failure process of the joint specimen $\left(45^{\circ}\right)$.

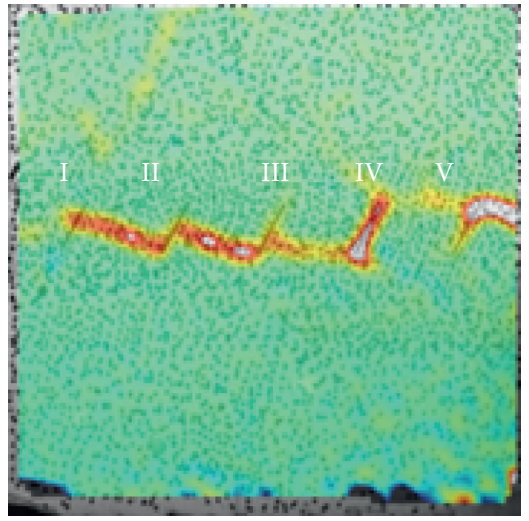

(a)

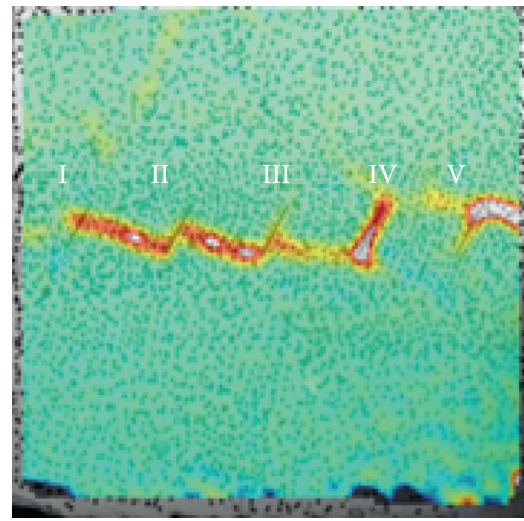

(b)

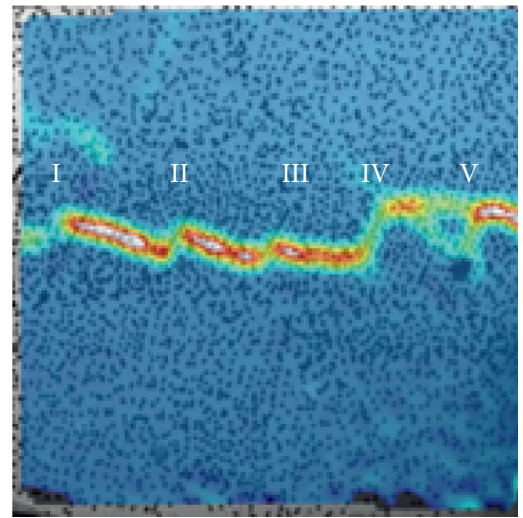

(c)

Figure 25: Failure process of joint specimens $\left(60^{\circ}\right)$.

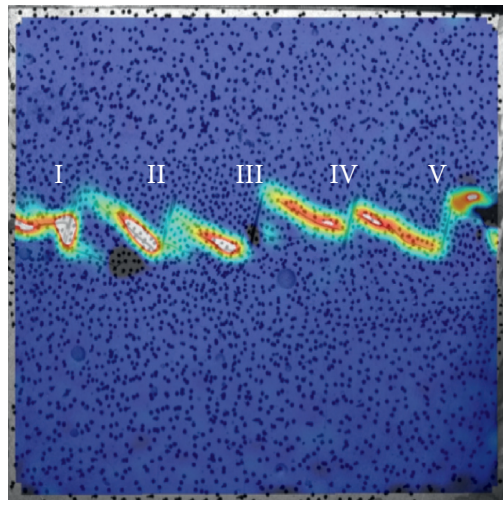

(a)

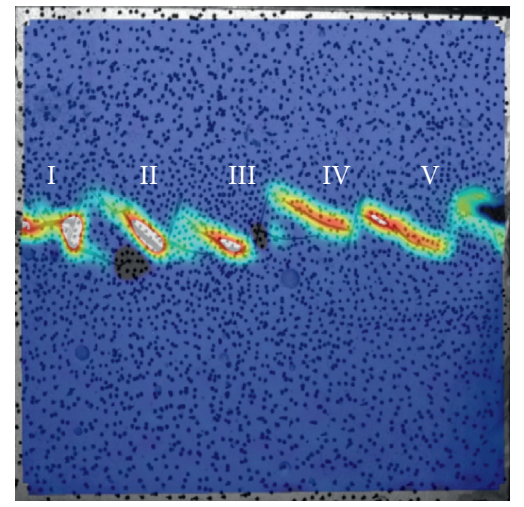

(b)

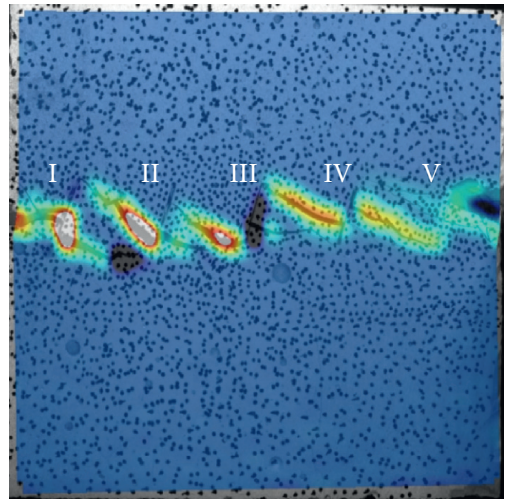

(c)

Figure 26: Failure process of the joint specimen $\left(75^{\circ}\right)$.

seen that the left middle part of joint I shows a $Y$-shaped crack to the left. On the right side, the joint extends from the underlying end of the joint to the $15^{\circ}$ direction below the right side, and the joint II penetrates and cracks from the underlying end of the left joint to the up-warped end of the left joint and then cracks horizontally from $1 / 3$ of the right underlying end to the right. The joint III penetrates and cracks from the underlying end of the left to $1 / 3$ of the left joint up-warped end and then horizontally cracks from $1 / 3$ of the underlying end of the left joint to the right. The joint IV penetrates and cracks from $1 / 3$ of the left underlying end to the left up-warped end and then cracks and penetrates from $1 / 3$ of the right underlying end to the right up-warped end. The joint $\mathrm{V}$ cracks horizontally to the left from the up- 


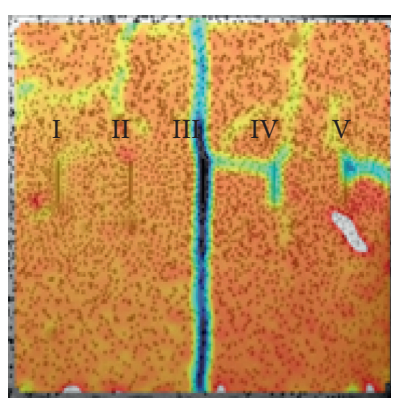

(a)

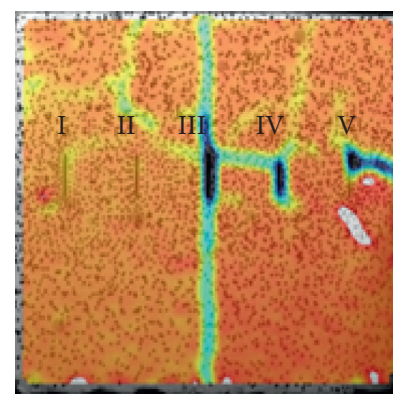

(b)

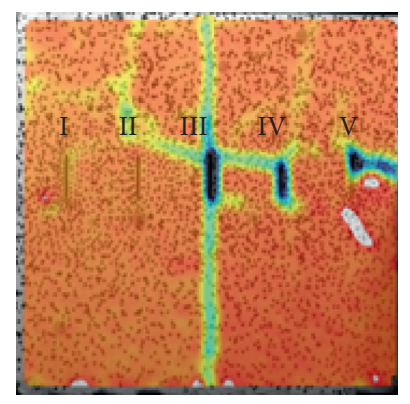

(c)

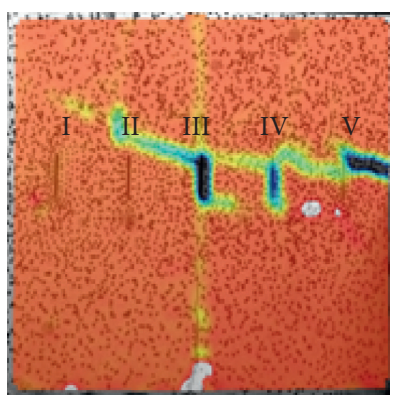

(d)

FIgURE 27: Failure process of the joint specimen $\left(90^{\circ}\right)$

warped end of the left joint and finally connects with the upwarped end of the right joint. Then, from the right joint upwarped end, the two fractures start to crack horizontally to the right. The joints finally connect with the right underlying end.

Figure 27 shows the typical development process of shear failure of the joint specimen with a dip angle of $90^{\circ}$. It can be seen that the right side of joint $\mathrm{V}$ cracks from the upper end of the joint and extends to the right underlying end by $60^{\circ}$ and then turns to expand horizontally to the edge of the specimen. The joint IV starts from the upper $1 / 4$ of the left joint and expands to joint III to form a tensile crack. It can be seen from Figure 27(c) that the crack at the bottom center expands upwards. Joint II expands horizontally from the upper end of the left joint to the left and then develops horizontally from the underlying end of the right joint to the right.

From the above analysis, it can be found that the joint dip angle has a significant influence on the evolution process of the shear strain of the joint specimen and the variation law of the maximum shear strain. The joint dip angle also has a significant influence on the crack initiation position and tensile failure. With the increase of load level, the maximum shear strain of joint specimens with joint dip angles of $0^{\circ}, 15^{\circ}$, $30^{\circ}, 60^{\circ}$, and $90^{\circ}$ increases slowly first and then increased rapidly. However, the maximum shear strain of the joint specimens with $45^{\circ}$ and $75^{\circ}$ joint dip angles keeps still small when reaching $100 \%$ of the peak load. When the dip angle of the fracture is less than $45^{\circ}$, cracks initiate at the joint tip. The cracks generated by adjacent fractures are directly connected, and finally, a transfixion fracture is formed. When the dip angle of the fracture is greater than $45^{\circ}$, the crack initiates at the joint tip, and secondary cracks expand approximately along the loading direction in the middle of the preset fracture and may stagger along different paths, resulting in shearing and crushing failure.

\section{Conclusions}

In this paper, the experimental study of different preset nontransfixion fracture dip angles was carried out, and the shear mechanical properties of the specimens with different fracture dip angles were discussed. Based on digital image correlation technology, the shear strain field of the model shear process was monitored in real time. The research results provided an important experimental reference for revealing the mechanism of shear crack initiation, expansion, and instability of preset rock. The conclusions are as follows:

(1) The joint dip angle has a significant influence on the evolution process of shear strain and the change law of maximum shear strain of the joint specimen. With the increase of the load level, the maximum shear strain of joint specimens with joint dip angles of $0^{\circ}$, $15^{\circ}, 30^{\circ}, 60^{\circ}$, and $90^{\circ}$ increases slowly first and then rapidly increased to a large value due to an obvious shear failure. However, the maximum shear strain for the specimens with joint dip angles $45^{\circ}$ and $75^{\circ}$ gradually increases to a relatively small value.

(2) The joint dip also has a significant influence on the crack initiation position and tensile fracture. When the dip angle of the crack is less than $45^{\circ}$, with the increase of the joint dip angle, the crack initials at the joint tip and expands to form a transfixion fracture.

(3) When the dip angle of the fracture is higher than $45^{\circ}$, the crack initiates at the crack tip, and a secondary crack approximately extends along the loading direction to the middle of the preset fracture. The secondary crack may be staggered along different paths, resulting in the crushing failure of rock bridges. When the joint dip angle is $90^{\circ}$, not only the fracture expands from the joint tip to the adjacent joint but the fractures also propagate perpendicular to the shear loading direction and form vertical transfixion fractures in the specimens.

\section{Data Availability}

Previously reported data were used to support this study. These prior studies (and datasets) are cited at relevant places within the text as references [1-32].

\section{Conflicts of Interest}

The authors declare that they have no conflicts of interest.

\section{Acknowledgments}

This work was supported by the National Natural Science Foundation of China (51774022) and National Key Research and Development Program of China (no. 2018YFE0101100). 


\section{References}

[1] H. K. Singh and A. Basu, "A comparison between the shear behavior of 'real' natural rock discontinuities and their replicas," Rock Mechanics and Rock Engineering, vol. 51, no. 1, pp. 329-340, 2018.

[2] L. P. Li, D. Y. Chen, and S. C. Li, "Numerical analysis and fluid-solid coupling model test of filling-type fracture water inrush and mud gush," Geomechanics and Engineering, vol. 13, no. 6, pp. 1011-1025, 2017.

[3] L. P. Li, S. C. Li, and Y. Zhao, "3D geomechanical model for progressive failure progress of weak broken surrounding rock in super large section tunnel," Chinese Journal of Rock Mechanics and Engineering, vol. 31, no. 3, pp. 550-560, 2012, in Chinese.

[4] E. Z. Lajtai, "Shear strength of weakness planes in rock," International Journal of Rock Mechanics and Mining Sciences \& Geomechanics Abstracts, vol. 6, no. 5, pp. 499-515, 1969.

[5] E. Z. Lajtai, "Strength of discontinuous rocks in direct shear," Géotechnique, vol. 19, no. 2, pp. 218-233, 1969.

[6] C. Gehle and H. K. Kutter, "Breakage and shear behaviour of intermittent rock joints," International Journal of Rock Mechanics and Mining Sciences, vol. 40, no. 5, pp. 687-700, 2003.

[7] H. B. Li, H. Feng, and B. Liu, "Study on strength behaviors of rock joints under different shearing deformation velocities," Chinese Journal of Rock Mechanics and Engineering, vol. 25, no. 12 , pp. 2 435-2 440, 2006, in Chinese.

[8] X. Xi, Z. Q. Yin, S. T. Yang, and C. Q. Li, "Using artificial neural network to predict the fracture properties of the interfacial transition zone of concrete at the mesoscale," Engineering Fracture Mechanics, vol. 242, no. 4, pp. 786-793, Article ID 107488, 2020.

[9] D. F. Yang, D. Y. Zhang, and S. G. Niu, "Uniaxial compression experimental study on crack propagation process and macroscopic failure mode of pre fractured fine sandstone," Journal of Mining and Safety Engineering, vol. 36, no. 4, pp. 786-793, 2019.

[10] R. S. Yang, W. Y. Li, and S. Z. Fang, "Experimental study on impact dynamic characteristics of layered composite rock mass," Journal of Rock Mechanics and Engineering, vol. 38, no. 9, pp. 1747-1757, 2019.

[11] C. C. Xia, Y. L. Song, and Z. C. Tang, "Particle flow numerical simulation for shear behavior of rough joints," Chinese Journal of Rock Mechanics and Engineering, vol. 31, no. 8, pp. 1545-1552, 2012, in Chinese.

[12] Y. Zhou, A. Misra, and S. C. Wu, "Macro-and meso-analyses of rock joint direct shear test using particle flow theory," Chinese Journal of Rock Mechanics and Engineering, vol. 31, no. 6, pp. 1245-1256, 2012, in Chinese.

[13] M. S. Asadi and V. Rasouli, "A bonded particle model simulation of shear strength and asperity degradation for rough rock fractures," Rock Mechanics and Rock Engineering, vol. 45, no. 5, pp. 649-675, 2012.

[14] A. P. S. Selvadurai and Q. Yu, "Mechanics of a discontinuity in a geomaterial," Computers and Geotechnics, vol. 32, no. 2, pp. 92-106, 2005.

[15] G. Wang, Y. Zhang, Y. Jiang, S. Wang, and W. Jing, "Macromicro failure mechanisms and damage modeling of a bolted rock joint," Advances in Materials Science and Engineering, vol. 2017, Article ID 1627103, 15 pages, 2017.

[16] N. Li, "Progress and thinking of experimental research on fractured rock mass," Chinese Society of Rock Mechanics and Engineering, vol. 7, 2002.

[17] Z. Q. Zhang, N. Li, and F. F. Chen, "Research status and Thinking on failure mode of non through fractured rock mass," Geotechnical Mechanics, vol. 30, no. S2, pp. 142-148, 2009.

[18] M. Prudencio and M. Van Sint Jan, "Strength and failure modes of rock mass models with non-persistent joints," International Journal of Rock Mechanics and Mining Sciences, vol. 44, no. 6, pp. 890-902, 2007.

[19] M. Bahaaddini, G. Sharrock, and B. K. Hebblewhite, "Numerical investigation of the effect of joint geometrical parameters on the mechanical properties of a non-persistent jointed rock mass under uniaxial compression," Computers and Geotechnics, vol. 49, pp. 206-225, 2013.

[20] W. S. Zhu, Z. C. Li, and W. Z. Chen, Failure Mechanism and Anchoring Effect of Jointed Rock Mass and its Engineering Application, Science Press, Beijing, China, 2002.

[21] Y. M. Liu and C. C. Xia, "Preliminary study on the weakening mechanism of mechanical properties of rock bridges with discontinuous joints under direct shear condition and the breakthrough model," Geotechnical Mechanics, vol. 31, no. 3, pp. 695-701, 2010.

[22] Y. S. Chen and N. Li, "CT experimental study on fracture propagation law of non through fractured media," Acta Rock Mechanics and Engineering, vol. 24, no. 15, pp. 2665-2670, 2005.

[23] S. Q. Yang, Y. H. Dai, and L. J. Han, "Uniaxial compression test study on deformation and failure characteristics of brittle marble with intermittent prefabricated cracks," Journal of Rock Mechanics and Engineering, vol. 28, no. 12, pp. 23912404, 2009.

[24] M. Chen, Study on Failure Mechanical Characteristics and Anchorage Control Mechanism of Intermittent Jointed Rock Mass, China University of Mining and Technology, Xuzhou, China, 2019.

[25] W. H. Peters and W. F. Ranson, "Digital imaging techniques in experimental stress analysis," Optical Engineering, vol. 21, no. 3, pp. 427-431, 1982.

[26] Y. Tang, S. Okubo, J. Xu, and S. Peng, "Progressive failure behaviors and crack evolution of rocks under triaxial compression by $3 \mathrm{D}$ digital image correlation," Engineering $\mathrm{Ge}$ ology, vol. 249, pp. 172-185, 2018.

[27] D. Li, Q. Zhu, Z. Zhou, X. Li, and P. R. Ranjith, "Fracture analysis of marble specimens with a hole under uniaxial compression by digital image correlation," Engineering Fracture Mechanics, vol. 183, 2017.

[28] S. Miao, P.-Z. Pan, Z. Wu, S. Li, and S. Zhao, "Fracture analysis of sandstone with a single filled flaw under uniaxial compression," Engineering Fracture Mechanics, vol. 204, pp. 319-343, 2018.

[29] X. Xi, X. Wu, Q. Guo, and M. Cai, "Experimental investigation and numerical simulation on the crack initiation and propagation of rock with pre-existing cracks," IEEE Access, vol. 8, 2020.

[30] W.-W. Ji, P.-Z. Pan, Q. Lin, X.-T. Feng, and M.-P. Du, "Do disk-type specimens generate a mode II fracture without confinement?" International Journal of Rock Mechanics and Mining Sciences, vol. 87, pp. 48-54, 2016.

[31] H. Su, H. Jing, and L. Yu, "Mode I fracture behaviour of sandstone after heat treatment," Géotechnique Letters, vol. 7, no. 1, pp. 1-6, 2017.

[32] S. Miao, P.-Z. Pan, P. Yu, S. Zhao, and C. Shao, "Fracture analysis of Beishan granite after high-temperature treatment using digital image correlation," Engineering Fracture Mechanics, vol. 225, Article ID 106847, 2019. 